Chapman University

Chapman University Digital Commons

Business Faculty Articles and Research

Business

2-12-2019

\title{
Counterparty Risk and the Establishment of the New York Stock Exchange Clearinghouse
}

\author{
Asaf Bernstein \\ University of Colorado, Boulder \\ Eric Hughson \\ Claremont McKenna College \\ Marc Weidenmier \\ Chapman University, weidenmi@chapman.edu
}

Follow this and additional works at: https://digitalcommons.chapman.edu/business_articles

Part of the Economic History Commons, Economic Theory Commons, and the Other Economics Commons

\section{Recommended Citation}

Bernstein, A., Hughson, E., \& Weidenmier, M. (2019). Counterparty risk and the establishment of the New York Stock Exchange Clearinghouse. Journal of Political Economy, 127(2), 689-729. doi: 10.1086/701033

This Article is brought to you for free and open access by the Business at Chapman University Digital Commons. It has been accepted for inclusion in Business Faculty Articles and Research by an authorized administrator of Chapman University Digital Commons. For more information, please contact laughtin@chapman.edu. 
Counterparty Risk and the Establishment of the New York Stock Exchange Clearinghouse

\section{Comments}

This article was originally published in Journal of Political Economy, volume 127, issue 2, in 2019. DOI: $10.1086 / 701033$

\section{Copyright}

University of Chicago Press 


\title{
Counterparty Risk and the Establishment of the New York Stock Exchange Clearinghouse
}

\section{Asaf Bernstein}

University of Colorado at Boulder

\section{Eric Hughson}

Claremont McKenna College

\section{Marc Weidenmier}

Chapman University and National Bureau of Economic Research

\begin{abstract}
We examine the effect of the establishment of the New York Stock Exchange (NYSE) clearinghouse in 1892 on counterparty risk using a novel historical experiment. During this period, the NYSE stocks were dual-listed on the Consolidated Stock Exchange (CSE), which already had a clearinghouse. Using identical securities on the CSE as a control, we find that the introduction of multilateral net settlement through a clearinghouse substantially reduced volatility of NYSE returns caused by settlement risk and increased asset values. Our results indicate that a clearinghouse can improve market stability and value through a reduction in network contagion and counterparty risk.
\end{abstract}

For more than a century, financial stability has depended on the resilience under stress of clearinghouses and other parts of the financial infrastructure. As we rely even more

We would like to thank Jinlin Ye for excellent research assistance and seminar participants at the Massachusetts Institute of Technology, Harvard Business School, Harvard Economic History, 2014 London Business School Summer Finance Symposium, University of Colorado-Boulder, and HEC Montreal. We would also like to thank Michael Greenstone, John Campbell, Randall Kroszner, Nittai Bergman, Neil Shephard, Eric Hilt, William Roberds, Vania Stavrakeva, Jun Pan, Adrien Verdelhan, Rajkamal Iyer, Haoxiang Zhu, 
heavily on these institutions in the United States and around the world, we must do all that we can to ensure their resilience, even as our financial system continues to evolve rapidly and in ways that we cannot fully predict. (Federal Reserve Chairman Ben Bernanke, April 4, 2011)

\section{Introduction}

On September 14, 2008, dealers from every major Wall Street firm involved in the $\$ 600$ trillion over-the-counter (OTC) derivatives market came in to work on a Sunday for an unprecedented emergency trading session. The goal? A frantic effort the day before Lehman Brothers declared bankruptcy to try to net counterparty risk in their bilateral OTC contracts with Lehman and limit the knock-on losses of its collapse on other financial institutions. Lehman's global OTC derivatives position at the time was estimated at $\$ 35$ trillion in notional value, which included being a counterparty in 930,000 derivatives transactions representing $\$ 24$ billion in counterparty liabilities. ${ }^{1}$ This ad hoc attempt at clearing was described by market participants as "a bust," with very little successful netting prior to Lehman's bankruptcy filing. ${ }^{2}$ The result was an unprecedented rise in counterparty risk, contagion, and financial instability among global financial market participants exemplified by a dramatic increase in indicators of counterparty risk including the credit default swap-bond basis and deviations from covered interest rate parity (Levich 2011; Giglio 2013).

The collapse of Lehman Brothers and the subsequent spillovers raised concerns about the role counterparty risk plays in the stability of the financial system and the importance of clearinghouses in mitigating that risk. In particular, policy makers in the United States and European Union have tried to address counterparty risk concerns not only by substantially increasing counterparty risk-based capital requirements for banks with Basel III but also by mandating centralized clearing of the majority of OTC derivatives via the Dodd-Frank and European Markets Infrastructure Regulation Acts. Prior to Lehman's collapse, OTC derivatives were

\footnotetext{
Jean-Noel Barrot, Erik Loualiche, Daan Struyven, Stephen Murphy, Nils Wernerfelt, Daniel Green, and Michael Abrahams for helpful comments. We greatly appreciate Janet Linde and the New York Stock Exchange Archives for their assistance in accessing historical archives. We also wish to thank the Lowe Institute of Political Economy and the Financial Economics Institute at Claremont McKenna College for financial support. Any errors are our own. Data are provided as supplementary material online.

${ }^{1}$ Lehman Brothers Holdings Inc. First Creditors Section 341 Meeting, January 29, 2009, Summe (2012), and their most recent 10Q filing on July 10, 2008.

${ }^{2}$ Financial Times, "Dealers Hold Emergency Trading Session," September 15, 2008.
} 
not required to engage in multilateral net settlement through a centralized clearinghouse and often relied on bilateral netting and ad hoc margin requirements between counterparties. Under bilateral netting, traders can be exposed to additional counterparty risk through contagion, since if one trader defaults he can set off a cascade of additional defaults. All else being equal, when OTC derivatives contracts instead engage in multilateral netting, Cecchetti, Gyntelberg, and Hollanders (2009) estimate that gross notional exposures can be reduced by as much as 90 percent. Policy makers point to these potential ex post netting benefits and the rise in counterparty risk concerns after Lehman's bankruptcy as evidence that mandated OTC derivative clearing would reduce the probability of an initial default as well as counterparty risk arising from contagion.

Despite the response of policy makers, academic evidence of the effects of centralized clearing on financial stability and asset values is still unclear. From a theoretical standpoint, Duffie and Zhu (2011) demonstrate that a single party clearing all assets should reduce counterparty risk, ceteris paribus, leading to lower volatility and higher asset value, but this result does not generalize to multiple clearinghouses or a single clearinghouse that does not clear all transactions. Acharya and Bisin (2014) establish that in the absence of a clearinghouse, there can be a counterparty externality that encourages excess risk taking; but Pirrong (2009) shows that a clearinghouse itself can reduce monitoring incentives, which subsequently increases moral hazard and counterparty risk. Biais, Hedier, and Hoerova (2012) also note that a reduction in idiosyncratic risk from clearing may endogenously increase systematic risk taking, and Menkveld, Pagnotta, and Zoican (2013) point out that if the introduction of a clearinghouse causes increases in collateral and margin requirements, then the effect of funding and market liquidity on asset prices makes the response of prices theoretically ambiguous (see also Garleanu and Pedersen 2011). Therefore, the effect of the introduction of a clearinghouse on asset prices remains inevitably an empirical question.

Unfortunately, empirical evidence on the role of centralized clearing is still limited and the effects on counterparty risk are mixed. Examining the introduction of a clearinghouse for Nordic equities in 2009, Menkveld et al. (2013) find that centralized clearing reduces asset values, but Loon and Zhong (2014) show that the centralized clearing of credit derivative contracts in 2009 actually increased their values. Interpretation of these opposing empirical results can be challenging because in both cases clearing was driven by the collapse of Lehman Brothers in the fall of 2008 and the resulting financial crisis. It is hard to know if the introduction of a clearinghouse in those markets was coincident with the subsequent deterioration or improvement in fundamental value and risk of those securities chosen to be cleared. It is precisely because the introduction of the 
clearinghouse was a response to a crisis that makes it problematic to attribute any changes in liquidity or counterparty risk to the clearinghouse and why it is important to control for economic conditions.

Fortunately, history provides an experiment to study the effects of a clearinghouse on counterparty risk where we can directly control for fundamental value. During the late nineteenth and early twentieth centuries, the Consolidated Stock Exchange (CSE) was a major exchange that competed head to head with the Big Board, traded many New York Stock Exchange (NYSE) listed securities, and, as noted by Brown, Mulherin, and Weidenmier (2008), averaged more than a 50 percent market share during the 1890s. Located across the street from the NYSE, the CSE netted stock transactions through a clearinghouse starting in 1886, while the NYSE did not until May of $1892 .{ }^{3}$ Neither exchange clearinghouse mutualized the risk of trading with a guarantee fund but rather facilitated multilateral netting across all members by centralizing clearing. Using identical securities on the two exchanges, we compare relative prices on the NYSE with those on the CSE both before and after the introduction of the NYSE clearinghouse, which allows us to control for changes in fundamental security value and volatility. This allows for clean identification of the causal effect on asset prices of the introduction of the clearinghouse by controlling for economic conditions in a way that is difficult to replicate with modern data. ${ }^{4}$ We also examine the relative prices for more than 30 years following the introduction of a clearinghouse, allowing us to observe the behavior during periods of relative calm and crisis as well as allowing time for endogenous general equilibrium effects by market participants.

We find that the introduction of netting on the NYSE increased the value of stocks relative to the CSE by 24 basis points (bp). Consistent with the findings by McSherry, Wilson, and McAndrews (2017), who document a decline in broker defaults on the NYSE after the introduction of clearing, the empirical results suggest that multilateral netting through an exchange clearinghouse increases rather than reduces equity values. Because brokers had to fund positions overnight, daily borrowing rates were a major determinant of counterparty risk. Prior to the introduction of clearing, a one standard deviation ( 3.7 percentage point) increase in the overnight collateralized borrowing rate for brokers, also known as the call loan rate, is associated with an 8 bp decline in the value of a stock on the NYSE relative to the identical security on the CSE. After the intro-

${ }^{3}$ The CSE began competing head to head with the NYSE in 1885 when the rival exchange began trading securities on the Big Board using their ticker. This action set off a lengthy legal battle between the two exchanges, with the NYSE ultimately establishing ownership of its price quotes (Mulherin, Netter, and Overdahl 1991).

${ }^{4}$ The beginning of multilateral net settlement through a clearinghouse on the NYSE in 1892 was driven by a variety of factors, most notably financial panics in the early $1890 \mathrm{~s}$ (McSherry and Wilson 2013). This again highlights the need to use the CSE as a control to cleanly identify the effect of counterparty risk. 
duction of clearing, shocks to the call loan rate no longer affect prices on the NYSE relative to the CSE, suggesting a decline in the volatility of NYSE prices. Consistent with this prediction, we find that relative to the CSE, NYSE daily return volatility due to settlement risk is reduced by as much as 26.9 percent of daily fundamental volatility, immediately following the introduction of centralized clearing, and remains low, even during subsequent financial crises, in the subsequent 34 years.

Centralized clearing on the NYSE was also introduced in stages, so we also examine the staggered introduction and find that at least half of the average reduction in counterparty risk is driven by a reduction in contagion risk through spillovers in the trader network. We run a series of robustness tests to demonstrate that our results are driven by changes in counterparty risk coming from the introduction of clearing rather than changes in asynchronous trading, market liquidity improvements on the NYSE, a decrease in market liquidity on the CSE, or financial crises. This includes showing that our results hold when using prices for dual-listed securities on the Boston Stock Exchange instead of the CSE as a control. Our results do not hold, however, without the CSE control, demonstrating again the importance of controlling for macroeconomic changes in fundamental value and volatility coincident with the introduction of a clearinghouse. We also find that the introduction of mutualization of risk and a formal centralized counterparty (CCP) by the NYSE clearinghouse in April of 1920 does not alter the benefits found from the introduction of centralized clearing with multilateral netting in 1892, providing additional evidence consistent with a role for CCPs in improving financial stability in asset markets. ${ }^{5}$

Section II begins with a brief historical background on the introduction of centralized clearing on the NYSE. We describe the data used in Section III. In Section IV, we present the empirical methodology and predictions. We discuss the empirical results in Section V. Section VI concludes the paper.

\section{Historical and Institutional Background}

\section{A. Trading on the NYSE Prior to Clearing}

Like OTC derivatives today, NYSE equities settled on a bilateral rather than a multilateral basis prior to the introduction of a clearinghouse in 1892. In the absence of multilateral netting, brokers are required to write and receive checks/securities for every transaction. To illustrate, consider the hypothetical set of transactions in figure 1. Broker A sells

\footnotetext{
${ }^{5}$ Risk mutualization, which is employed by the 1920 clearinghouse but not the 1892 clearinghouse, is netting by novation, in which the clearinghouse becomes the counterparty for each side of the netted transaction balances.
} 


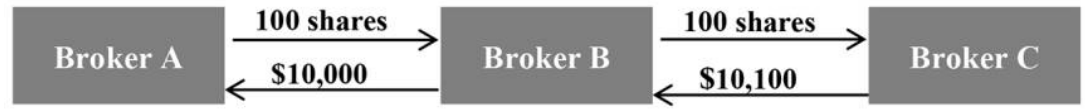

Next day deliverables:

Shares: 200

Cash: $\$ 20,100$

FIG. 1.-Example 1: visual representation of bilateral trades between three brokers

100 shares of stock for $\$ 10,000(\$ 100 /$ share $)$ to broker $\mathrm{B}$, and later in the day $\mathrm{B}$ sells 100 shares to $\mathrm{C}$ for $\$ 10,100$. In the absence of multilateral netting, broker C owes a check to broker B for $\$ 10,100$ and broker B would owe a check to broker A for $\$ 10,000$, resulting in $\$ 20,100$ of checks and 200 shares of stock being transferred. There are direct counterparty risks since, for example, if broker B defaults (and has no wealth), broker A loses $\$ 10,000$; but there is also a possibility of large spillovers causing contagion counterparty risk throughout the trading network. For example, if broker C defaults (and has no wealth), broker B loses $\$ 10,100$. If in turn this pushes broker B into default (and again has no wealth), then A loses $\$ 10,000$. As we add more brokers into the network, the chain of defaults can multiply. Depending on how interconnected the trading network is, the spillover from contagion could be a substantial component of total counterparty risk. Eliminating counterparty risk for security A should also reduce the counterparty risk of security $\mathrm{B}$ even if it is unrelated because there is less chance of a broker, or brokers he is trading with, defaulting on positions. For clarity we refer to the counterparty risk caused by network spillovers as contagion risk and the remaining risk as direct counterparty risk.

At the time the NYSE clearinghouse was introduced, securities traded on the NYSE settled at time $T+1$, which meant all brokers were required to deliver gross checks/securities from trades by the next day at 2:15 p.m. Brokers engaged in transactions with numerous other brokers throughout the day, so they rarely had enough assets on hand to pay every single transaction. Customers also bought securities on margin, so brokers would often have to borrow the additional funds necessary. Therefore, banks were forced to extend significant uncollateralized credit and day loans to brokers to allow them to fulfill their daily contracts. This practice was called overcertification since banks endorsed checks that certified an amount greater than the balance in the broker's account, effectively providing short-term leverage to brokers to finance their daily positions. ${ }^{6}$ This bears similarities to modern broker-dealers who use the repo market

${ }^{6}$ While technically illegal, overcertification was endemic during the period and was used by most brokers and banks to finance their overnight positions. 
and asset-backed commercial paper to provide short-term financing for trades in the OTC markets. ${ }^{7}$ McSherry and Wilson (2013) find that leverage, measured as the value of certified checks divided by total capital, for nine "broker banks," increased from 1.4 to 9.0 from 1875 to 1882 . Anecdotal evidence suggests even higher leverage ratios in the 1890s.

Just as short-term collateralized financing rates in the modern period are set by repo rates, brokers would also finance positions via overnight collateralized borrowing organized on the floor of the NYSE. The rate to buy and sell securities on margin via these overnight collateralized loans was known as the call loan rate. The call loan rate could fluctuate wildly depending on the market environment. Short-term interest rates were prone to seasonal increases during the harvest months and tended to increase dramatically during late nineteenth- and early twentieth-century banking panics (Miron 1986; Bernstein, Hughson, and Weidenmier 2010). For example, the call loan rate reached a daily annualized value of 125 percent during the Panic of 1907 (Moen and Tallman 2003).

The volatility of funding costs to finance overnight positions led to a significant number of broker defaults and increased counterparty risk. McSherry et al. (2017) find evidence of a statistically significant relationship between spikes in call loan rates and broker insolvencies during this period. Contemporaneous researchers, such as Sprague (1910), also blamed the immediacy of the liquidity requirements inherent in the NYSE system of daily settlement for broker failures, which tended to spike during periods of financial stress. During periods of panic, buyers might walk away from buy orders, leaving brokers with losses and potential defaults on overcertified checks. Anticipating this outcome, Wall Street banks and trust companies that normally participated in overcertification might withdraw the privilege extended to brokers. This is exactly what happened in the Panic of 1873, when banks suspended overcertification to NYSE brokers. This action led to a suspension of trading for 9 days and 57 broker failures (Eames [1894] 1968). Pratt (1909) notes that by early 1892, R. L. Edwards, the president of the Bank of the State of New York, threatened that certification for brokers would be cut unless decisive action was taken to lessen the strain on bank lending and clerks. ${ }^{8}$ NYSE president Francis L. Eames subsequently pushed for the creation of the NYSE clearinghouse in May of 1892, which engaged in multilateral netting across all NYSE members (Pratt 1909).

\footnotetext{
${ }^{7}$ It is worth noting, though, that while lending in modern repo markets also extends massive credit on an intraday basis, this lending is done on a fully collateralized basis. We thank an anonymous referee for raising this point.

${ }^{8}$ Meeker (1922) also documents that without the introduction of multilateral netting, it would have been physically impossible to maintain daily settlement. If, however, physical constraints rather than counterparty risk were the main reason for the introduction of multilateral netting, a perhaps more plausible response would have been to increase the settlement period.
} 
The NYSE clearinghouse function would then be extended in April of 1920 to include mutualization of risk by acting as a centralized counterparty on trades between all members. The staggered timing of the introduction of centralized clearing and then mutualization of risk provide a novel setting to try to distinguish the effects of the two major functions of modern clearinghouses. ${ }^{9}$ The analysis in 1920 is made more challenging though since accusations of fraud on the CSE in February of 1922, which led to its eventual downfall, limit our identification strategy in the post-mutualization period. We therefore focus our primary analysis on the introduction of centralized clearing in 1892 but also briefly examine the introduction of mutualization in 1920.

\section{B. Timing of the Introduction of Centralized Clearing on the NYSE}

On May 17, 1892, the NYSE introduced multilateral netting for four stocks. The decision to introduce centralized clearing was driven by the financial panics of the early 1890s, concerns that banks would restrict overcertification again, as well as evidence on the effectiveness of multilateral netting used on the CSE. ${ }^{10}$ Because many NYSE stocks were already centralized clearing on the CSE, we can disentangle the effects of economic events from the effects of centralized clearing on counterparty risk. As indicated in the clearinghouse meeting minutes, the NYSE had prescheduled meeting dates and decided that "the list of stocks to be cleared will be enlarged as members become familiar with the clearing system." Since having some NYSE stocks clearing had spillover benefits through a reduction in contagion risk for the remainder, the staged and independent timing of the introduction of multilateral netting for different securities allows separate identification of contagion and direct counterparty risk. The NYSE continued to have meetings and clear addi-

\footnotetext{
${ }^{9}$ Securities market clearinghouses serve two primary and distinct functions: multilateral netting and mutualization of risk. Since clearinghouses observe all trades on a given exchange, they can net transactions across traders in an attempt to reduce the size of outstanding liabilities and subsequent counterparty risk. The NYSE clearinghouse in 1892 engaged in exactly this sort of netting function, which is the primary function of clearing analyzed in this paper. In today's regulatory environment, clearinghouses are also typically mandated to provide mutualization of risk by including themselves as counterparties in all transactions. In order to more clearly assess the modern implications of our analysis, we also explore the introduction of mutualization of risk by the NYSE clearinghouse in 1920 but are limited by the length of time available for our empirical methodology in the post-mutualization period.

${ }^{10}$ In fact, by 1892 there were numerous examples of effective clearing systems in the United States, including the establishment of a clearinghouse for New York City bank deposits in 1853 (Gorton 1985) and for commodity trading on the Chicago Board of Trade in 1883 (Kroszner 1999).
} 
tional stocks throughout the 1890s, and by the end of 1893, most of the major securities were clearing. ${ }^{11}$

\section{Trading on the NYSE after Centralized Clearing}

To understand the benefits of the introduction of centralized clearing on the NYSE, we examine multilateral netting between three brokers. A hypothetical set of transactions is shown in figure 2. Each transaction a broker made was recorded on the broker's clearance sheet for a given day. In our example, A's clearance sheet had a single sale, C's clearing sheet had a single purchase, and B's clearance sheet had a purchase and a sale. It is at this stage that netting occurred, and here, netting occurred only for B. Broker B bought 100 shares for $\$ 10,000$ and then immediately sold them for $\$ 10,100$. $^{12}$ The purchase and sale were netted out and $B$ received the difference of $\$ 100$. Broker $\mathrm{A}$ had a balance to deliver 100 shares valued at $\$ 10,000$ and $\mathrm{C}$ had a balance to deliver of $\$ 10,100$. Therefore, A wrote a draft on the clearinghouse of $\$ 10,000$, B wrote a draft for $\$ 100$, and $\mathrm{C}$ wrote a check to the clearinghouse for $\$ 10,100$. By 10:00 a.m. the next day, the clearinghouse returned a complete statement to each firm, specifying to whom a delivery must be made by 2:15 p.m. that day (here A delivered to C). Creditors to the clearinghouse received checks for their remaining balances by noon, which were then deposited in the bank (American Bankers Association 1910). ${ }^{13}$

Under gross bilateral clearing, there were $\$ 20,100$ worth of checks and 200 shares that could be defaulted on; but after multilateral netting there were only $\$ 10,100$ worth of checks and 100 shares to be transferred. In this case there is a reduction in direct ex post counterparty risks since with multilateral netting, if broker $\mathrm{B}$ defaulted (and had no wealth), broker A lost nothing. There was also a reduction in spillovers causing contagion counterparty risk throughout the trading network. For example, if broker $\mathrm{C}$ defaulted (and had no wealth), broker A lost $\$ 10,000$; and if broker A defaulted (and had no wealth), broker B lost only $\$ 100$. With multilateral netting, typically the chain of defaults does not grow as quickly as it would with bilateral netting when we add more brokers into the network.

\footnotetext{
${ }^{11}$ For example, by the end of 1893 more than 80 percent of NYSE volume in Dow Jones stocks was clearing.

12 This simple example overlooks one complication. In reality, for ease of netting, delivery prices were not simply what one paid or sold his or her shares for, but were instead determined by the clearinghouse. At the end of each day, representatives set a price based on the quotation of the last day's sales, which was then announced over the ticker. Small additional checks were then written between parties to account for the differences between the delivery prices and the actual executed prices (Pratt 1909).

13 These exact times may have varied throughout the years, but they provide a rough picture of the daily operations of the clearinghouse.
} 


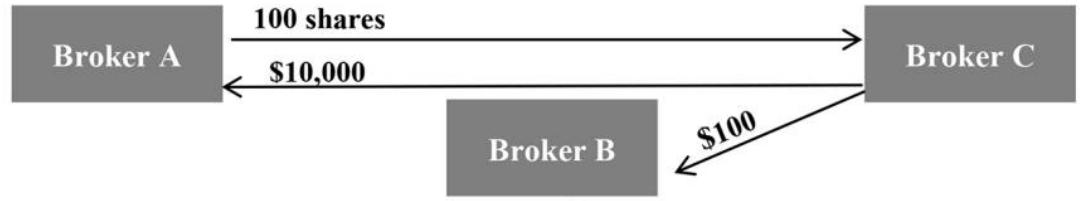

Next day deliverables:

Shares: 100

Cash: $\$ 10,100$

FIG. 2.-Example 2: visual representation of trades between three brokers with clearing.

Anecdotal evidence suggests that the NYSE clearinghouse may have been successful in reducing counterparty risk on the NYSE in the years immediately following its establishment. In the post-clearinghouse period (i.e., between 1892 and 1920), Pratt (1909) estimated that the demand for day loans from certifying banks decreased by nearly 65 percent, and 90 percent of all checks were eliminated. On average, transactions in securities valued at $\$ 25$ million necessitated only $\$ 5$ million to change hands. In one case, 204,000 shares, valued at $\$ 12.5$ million, were settled by a payment of only $\$ 10,000$ (Meeker 1922).

That being said, anecdotal evidence of the effect of multilateral netting on counterparty risk through contagion is mixed. The Chicago Board of Trade introduced a "ring" settlement system in 1883 similar to the one introduced on the NYSE, and in 1902 the bankruptcy of member George Phillips led to losses for more than 42 percent of members of the board (Moser 1998; Kroszner 1999). Direct measures of broker insolvencies also may not necessarily provide the full picture, since changes in counterparty risk caused by a clearinghouse could lead to differences in margin requirements, borrowing rates, and commissions between customers, brokers, and/or banks. The aggregate effect of all these channels should show up in prices, through either expected losses from counterparties or changes in the discount rate coming from volatility in counterparty risk and/or margin-driven asset pricing changes (Garleanu and Pedersen 2011). Another challenge in interpreting effects is controlling for the counterfactual changes in broker defaults and security value and volatility in the absence of a clearinghouse.

\section{Consolidated Stock Exchange: An Almost Ideal Control}

As illustrated in the time line in figure 3, the CSE, also known as the "Little Board," was established in New York City in 1885 with 2,403 members and provides an excellent control for our difference-in-difference anal- 


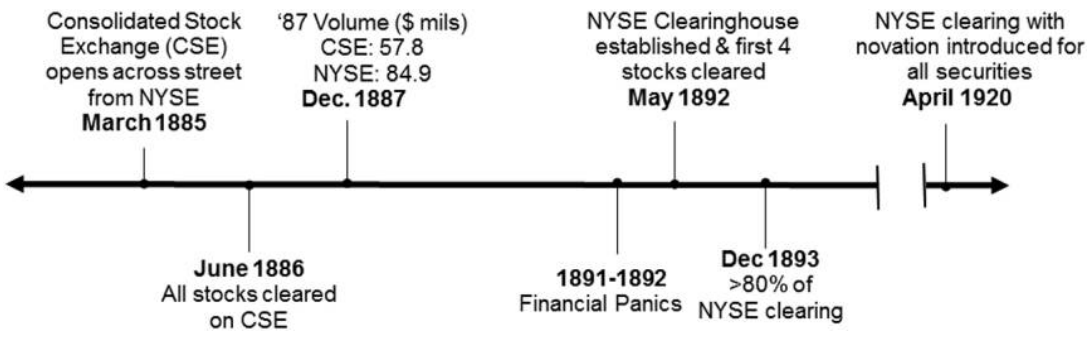

FIG. 3.-Time line of introduction of centralized clearing on the NYSE and CSE. This time line shows the introduction of a clearinghouse on the CSE in June 1886 and the introduction in stages on the NYSE beginning in May 1892. Data on trading volumes are taken from Sobel (2000).

ysis of the effect of the introduction of clearing. ${ }^{14}$ The Little Board competed head to head with the NYSE (Michie 1986). The rival exchange averaged a respectable 23 percent market share (Brown et al. 2008) over its 40-year history, although CSE stocks generally had less trading volume and market liquidity than the same security on the Big Board. ${ }^{15}$ While the NYSE waited until 1892 to introduce clearing, the CSE began multilateral net settlement in 1886. As noted by McSherry and Wilson (2013, 23), one reason that the NYSE introduced centralized clearing was that the CSE had "reduced financing needs and also lowered counterparty risk and broker defaults" by netting through a clearinghouse.

We provide some suggestive evidence of the impact of the clearinghouse on the CSE by hand-collecting information on broker defaults from the annual reports of the Consolidated Stock and Petroleum Exchange of New York. Consistent with the contemporaneous accounts, the CSE clearinghouse was successful in minimizing counterparty risk. We find that losses from broker defaults were less than 0.03 percent of total trading volume in 1893, a year that included one of the most severe financial panics in American history, despite the fact that many of the old-guard NYSE members at the time considered the much younger and smaller upstart CSE to be less reputable (Brown et al. 2008). ${ }^{16}$

\footnotetext{
${ }^{14}$ Figures are based on annual reports of the Consolidated Stock and Petroleum Exchange of New York.

${ }^{15}$ Commission rates on the CSE averaged half the brokerage commission charged by the NYSE, but members trading with each other were charged rates as low as 1/32nd of par value (Michie 1986). The CSE also specialized in odd-lot trading, and while the NYSE required next-day settlement, the CSE required weekly or semiweekly settlement. Securities traded on both exchanges will allow us to control for the vast majority of variation in prices based on any changes in fundamental value, but we will still need to examine the role played by any differential trends in liquidity, specialization, and market participants on the two exchanges.

${ }^{16}$ Despite the fact that trading sizes and liquidity were lower on the CSE, without knowing more about the balances of the traders themselves, it is hard to say which exchange ac-
} 
Therefore, prices on the CSE for NYSE-CSE dual-listed stocks provide an almost ideal control for the price response on the NYSE to the introduction of clearing. ${ }^{17}$ This is why the introduction of centralized clearing on the NYSE can be used to identify the causal effects of multilateral netting. In addition to having cross-listed securities, we also benefit from the close proximity of the two exchanges. Since the two exchanges were across the street from each other, arbitrageurs could effectively prevent price discrepancies between the two exchanges not caused by "real differences" such as market illiquidity or counterparty risk premia. ${ }^{18}$ Nelson

tually had higher-risk market participants. Market participants on the CSE were likely to be smaller investors but because of this may have taken more conservative positions. This is made even more challenging since, as noted by Ott (2004), the NYSE ran a very successful public relations campaign from 1913 to 1929 using relationships at the New York State Attorney General's Office to damage the CSE's reputation, which makes it difficult from contemporaneous sources to separate reality from propaganda. For example, Shea $(1911,199)$ mentions that "many members after a successful career on the floor of the Consolidated, have become well-known factors on the New York Stock Exchange, and not one broker who has thus gone from the former to the latter has failed. As a school of brokerage the Consolidated is unrivaled." This passage was written prior to the public campaign against the CSE and highlights the likely view of the CSE as a younger exchange, but not one of obvious ill repute.

17 The CSE and NYSE also had similar governance structures and internal regulations. Both exchanges were cooperatively owned and governed by their members, with a board of governors, including a president, elected by members of the exchange, and committees with members appointed by the president overseeing various functions of the exchange. The constitution of both exchanges also allowed either party in the transaction for the sale or purchase of stocks, bonds, or any outstanding contracts to call, at any time, a mutual deposit of cash for margin, with as little as 30 minutes' notice. The NYSE and CSE allowed any party to demand maintenance margins of 5 percent, while the NYSE and CSE constitutions provided for initial margin requirements of 10 and 5 percent, respectively. We have found no change in the official margin requirements in either constitution after 1892, but in practice it is unclear if these minimal margin constraints were actually binding. As noted in a report by the CSE's governor's Committee on Securities and Commodities in 1909, "the amount of margin which a broker requires from a speculative buyer of stocks depends, in each case, on the credit of the buyer" (State of New York 1909, 9). On the basis of minutes from the NYSE's Insolvency Committee from 1876-1925, brokers were occasionally removed from the exchange because they required insufficient margins from customers. In one instance, for a trader they note that they "found that he was guilty of doing business in an unbusiness like manner i.e.: without margin." Even among this subset of potentially reckless brokers, the majority reported margins of 5-8 percent and sometimes as high as 25 percent, depending on the reported trustworthiness of customers. All additional information on governance structure comes from the Constitution of the New York Stock Exchange and Constitution of the Consolidated Stock Exchange from 1892.

${ }^{18}$ One way to conceptually think about these two exchanges could be to imagine one stock market with different venues for trading the same stocks. An arbitrageur observing stock A trading for $\$ 100 /$ share on the NSYE "venue" and \$101 on the CSE "venue" might be tempted to buy it on the NYSE and immediately sell on the CSE with the hope of a quick riskless profit. The problem is that if the arbitrageur executed a transaction to buy the NYSE security prior to the introduction of a clearinghouse and during a time of market duress, there is a significant risk that the counterparty in the deal would fail to settle on the next day and the arbitrageur could face substantial costs. The higher counterparty risk for the transaction on the NYSE should lead to a persistent time-varying price deviation of executing through each venue, even though the security itself and subsequently the underlying fundamental value are the same. We thank an anonymous referee for the motivation for this explanation. 
([1907] 1975) dedicates an entire chapter to the "expertise" of arbitrageurs on the CSE who were, he felt, exceeded in their expertise only by the arbitrageurs on the NYSE. In fact, in table A4 of the online appendix, we show that more than 92 percent of all variation of individual NYSE stock returns can be explained by the returns of identical securities listed at the same time on the CSE. ${ }^{19}$ Another benefit of their close proximity is that both exchanges paid in the same currency. Cross-listed securities in markets quoted in different currencies are confounded by the need to convert currencies using OTC foreign exchange (FX) markets. Normally this is not problematic, but since these markets are OTC, during times of financial distress, FX swaps may also include potentially significant counterparty risk. For example, Levich (2011) shows that immediately following the Lehman bankruptcy, covered interest rate parity in the highly liquid FX swap British pound/US dollar deviated from no arbitrage conditions (in the absence of counterparty risk) by hundreds of basis points. ${ }^{20}$

\section{Data Description}

\section{A. Security Market Data}

We focus our empirical analysis on common stocks in the Dow Jones indices using monthly data from September 1886 to December 1925 because these securities tended to be very liquid and traded on both the NYSE and CSE (Brown et al. 2008). We use the original Dow Jones index from September 1886 until October 1896, when the index is then split into the Dow Jones Railroad Index and the Industrial Index. We use hand-collected data from the New York Times and Commercial and Financial Chronicle for each security in the index at a given point in time and rely on Farrell (1972) for changes in the composition of the indices. Data are sampled from the last trading day of each month. We collected firmspecific information on NYSE high, low, open, and closing transaction prices; bid and ask closing prices; and trading volume. It is worth noting

\footnotetext{
19 By comparison, Lewellen (2014) regresses monthly stock returns on lagged individual firm stock returns, size, and book-to-market ratios and on average explains only 3.3 percent of cross-sectional variation in NYSE stock returns from 1964 to 2013. Even when including 15 lagged stock-specific individual factors expected to explain stock returns, he finds that less than 8 percent of cross-sectional variation in returns is explainable.

${ }^{20}$ Another benefit of proximity, besides the ones previously emphasized, is that since both exchanges were in the same time zone, daily data on opening and closing prices are easily comparable. The reason is not only that it reduces timing mismatches in the quotes but also that they are comparable periods of the trading day. Oftentimes opening and closing price behavior can behave differently, and while high-frequency quotes allow for quotations across time zones at the same time of day, this cannot be done while also preserving the period of the trading day considered.
} 
TABLE 1

NYSE AND CSE Summary Statistics

\begin{tabular}{|c|c|c|c|c|c|c|}
\hline & $\begin{array}{l}\text { NYSE } \\
\text { Closing } \\
\text { Price }\end{array}$ & $\begin{array}{c}\text { NYSE } \\
\text { Trading } \\
\text { Volume } \\
\text { (No. } \\
\text { Shares) }\end{array}$ & $\begin{array}{c}\text { CSE } \\
\text { Trading } \\
\text { Volume } \\
\text { (No. } \\
\text { Shares) }\end{array}$ & $\begin{array}{l}\text { NYSE Trading } \\
\text { Volume } \\
(\$ 000 \mathrm{~s})\end{array}$ & $\begin{array}{l}\text { CSE Trading } \\
\text { Volume } \\
(\$ 000 s)\end{array}$ & $\begin{array}{c}\text { NYSE } \\
\text { Bid-Ask } \\
\text { Spread } \\
\text { (bp) }\end{array}$ \\
\hline & \multicolumn{6}{|c|}{ With Minimum 1 Share Traded $(n=9,373)$} \\
\hline Mean & 84.4 & 13,726 & 3,241 & 1,352 & 322 & 52 \\
\hline Median & 81.4 & 4,400 & 410 & 324 & 29 & 32 \\
\hline $\begin{array}{l}\text { Standard } \\
\text { deviation }\end{array}$ & 42.4 & 29,340 & 8,710 & 3,304 & 965 & 66 \\
\hline Minimum & 4 & 5 & 5 & .2 & .04 & 7 \\
\hline \multirow[t]{2}{*}{ Maximum } & 323 & 489,444 & 291,870 & 52,300 & 24,100 & 1,818 \\
\hline & \multicolumn{6}{|c|}{ With Minimum 200 Shares Traded $(n=6,065)$} \\
\hline Mean & 85.5 & 19,911 & 4,958 & 1,972 & 493 & 41 \\
\hline Median & 81.0 & 8,425 & 1,150 & 644 & 88 & 26 \\
\hline $\begin{array}{l}\text { Standard } \\
\text { deviation }\end{array}$ & 41.1 & 34,912 & 10,432 & 3,966 & 1,164 & 52 \\
\hline Minimum & 4.7 & 200 & 200 & 3.6 & 1.4 & 7 \\
\hline Maximum & 319.5 & 489,444 & 291,870 & 52,300 & 24,100 & 1,481 \\
\hline
\end{tabular}

NotE.-This table reports the sample statistics for the trading data for stocks on the NYSE and the CSE. Security market data were hand-collected at a monthly frequency from the New York Times and Commercial and Financial Chronicle from September 1886 to December 1925 for all stocks in the Dow Jones indices. All data are winsorized at the 1st and 99th percentiles. To be included in the first level of summary analysis a security must trade at least one share on both exchanges on a given date, while for the second, which is the one used in our primary econometric specifications, we require at least 200 shares (two standard contracts).

in table 1 that, consistent with anecdotal accounts, liquidity on the CSE was worse than on the NYSE. Bid-ask spreads were higher and volume lower for identical securities. ${ }^{21}$ For NYSE stocks listed on the CSE, we use data on CSE closing prices as well as CSE trading volume. We also use hand-collected monthly data on seat prices for the NYSE and CSE for the period 1888-1925 from the Commercial and Financial Chronicle. In addi-

${ }^{21}$ As mentioned previously, when the CSE was first introduced, it specialized in trading odd lots of shares. Prior to volume rising dramatically after 1900, security trading days with total share volume greater than 200 shares among members of the Dow Jones indices with nonmultiples of 100 shares constituted 90 percent and 92 percent of security-days on the NYSE and CSE, respectively. This is consistent with the CSE engaging in more odd-lot trading than the NYSE but suggests that both the NYSE and CSE typically had at least one odd lot per security-day. This may not be too surprising since by this time the NYSE and CSE traded both odd and regular lots. For example, Ott (2004) shows that by 1921, 40 percent of business on the NYSE was for odd lots, and Shea $(1911,198)$ noted that "lots of 500 to 1,000 shares in single blocks are frequently turned over [on the CSE]." 
tion, we collect daily closing bid and ask quotes on the NYSE starting in 1893. ${ }^{22}$ We also use end-of-month broker call loan rates from the NBER macrohistory database for the entire sample period.

For robustness checks, we hand-collected daily data on high, low, closing, and opening transaction prices as well as trading volumes from January 1892 to December 1901 for all stocks on the NYSE, CSE, and the Boston Stock Exchange (BSE). Closing prices for the BSE are collected from the Boston Globe for 1892-1901 at a weekly frequency. We construct an absolute difference estimator using daily high, low, opening, and closing transaction prices to estimate CSE bid-ask spreads and NYSE bid-ask spreads prior to 1893. Our estimated NYSE bid-ask spreads have an 88 percent correlation with actual bid-ask spreads on the Big Board from 1892 to 1925. Our estimator performs slightly better in-sample than one used by Corwin and Schultz (2012), which has an 81 percent correlation with actual NYSE spreads over the same period. In addition, our estimator has the desirable property, since unlike that used by Corwin and Schultz, it is always positive, which was not the case for our Corwin-Schultz bid-ask estimates in our sample period. For more details on the methodology and a comparison of the bid-ask spreads, see appendix B.

\section{B. Clearinghouse Data}

The NYSE started centralized clearing securities in stages, beginning with four stocks on May 17, 1892, followed by four additional stocks each week. By 1894, more than 90 percent of volume was cleared on the exchange, and only a handful of stocks were subsequently added to the clearinghouse each year (based on authors' calculations). The dates stocks were added and dropped from centralized clearing on the NYSE were reported in the minutes of the Committee on the Clearinghouse of the New York Stock Exchange at the NYSE archives. The minutes of the clearinghouse were useful for understanding the function and implementation of netting trades on the exchange. Data on broker defaults on the NYSE were collected from the NYSE archives Committee on Admissions and List of Suspended Members. Information on CSE broker defaults were collected from the annual reports of the Consolidated Stock and Petroleum Exchange of New York.

${ }^{22}$ Beginning on May 24, 1882, the New York Times reports NYSE bid-ask spreads on a daily basis. The data on daily bid-ask spreads continue through April 14, 1886. Between April 15, 1886, and May 12, 1893, the New York Times does not report bid-ask spreads for the NYSE. In this time interval, we gather monthly bid-ask spread data from the Commercial and Financial Chronicle. The bid-ask spread data are reported for Thursday trading and are matched with the appropriate trading volume data from the New York Times. 


\section{Empirical Predictions and Methodology}

\section{A. Theoretical Predictions}

In the presence of counterparty risk and market liquidity costs, we can decompose the price of any traded asset into its fundamental value minus market liquidity costs and counterparty risk, plus any additional market microstructure noise:

$$
P_{i, t, E}=P_{i, t}^{F u n}-P_{i, t, E}^{M k t L q}-P_{i, t, E}^{C P}+\epsilon_{i, t, E},
$$

where $P_{i, t, E}$ is the price on exchange $E$ (except the NYSE) for stock $i$ at time $t ; P_{i, t}^{F u n}$ is the firm's exchange invariant fundamental value; $P_{i, t, E}^{M k t L q}$ is the discount caused by the market illiquidity premia, which include both the explicit and implicit costs of trading and how they covary with the pricing kernel ${ }^{23}$ (Acharya and Pedersen 2005; Brunnermeier and Pedersen 2009; Garleanu and Pedersen 2011); $P_{i, t, E}^{C P}$ is the discount caused by the counterparty risk premium; and $\epsilon_{i, t, E}$ is market microstructure noise with mean zero, such as bid-ask bounce. This decomposition arises naturally from the original framework of Amihud and Mendelson (1986), where investors who buy securities anticipate paying transactions costs when selling them, as do the next buyers. Consequently, when valuing the asset the investor rationally discounts the fundamental value by the present value of the expected future transaction costs. If we consider the same asset trading on two exchanges, $E$ and $E^{\prime}$, then even in the presence of active arbitrageurs, the price should differ whenever there are differential trading costs, liquidity, and counterparty risk by the following spread:

$$
P_{i, t, E}-P_{i, t, E^{\prime}}=P_{i, t, E^{\prime}}^{M k L q}-P_{i, t, E}^{M k L L q}+P_{i, t, E^{\prime}}^{C P}-P_{i, t, E}^{C P}+\epsilon_{i, l, E^{\prime}}-\epsilon_{i, t, E} .
$$

A substantial literature has documented these kinds of price spreads among securities paying the same cash flows. A few examples of such deviations include on-the-run Treasuries that trade at lower yields than offthe-run Treasuries (Amihud and Mendelson 1991), restricted resale stocks that trade at a substantial discount to publicly traded stock (Silber 1992), corporate bond versus identical name credit default swap (CDS) spreads (Duffie 2010), and corporate bond variations in spreads among identical CDS contracts (Arora, Gandhi, and Longstaff 2012). The sign of these deviations depends on the relative trading costs in both markets and whether costs are borne more by buyers or sellers. A number of empirical papers including work by Amihud (2002), Jones (2002), and Acharya and Pedersen (2005) have documented that in modern markets stocks that

\footnotetext{
${ }^{23}$ The explicit costs include commissions and the bid-ask spread, while implicit costs include price movement from larger orders (market depth), borrowing costs to finance the trading position (margin), and stocking additional inventory.
} 
are more illiquid trade at discounted prices and have higher expected returns. These results are also consistent with research on fire sales in asset prices (Coval and Stafford 2007; Benmelech and Bergman 2011) in which sellers of assets are those in need of liquidity and thus are willing to sell the security at a discount, which means that market illiquidity costs asymmetrically affect market participants and subsequently alter traded asset prices. So holding counterparty risk constant, if market liquidity were better (except lower bid-ask spreads) on exchange $E$ than on $E^{\prime}$, we would expect the prices for identical securities on $E^{\prime}$ to trade at a discount. If, on the other hand, market liquidity is lower on exchange $E$ but counterparty risk is higher on $E$ than on $E^{\prime}$, then the direction of the price spread is ambiguous. Since traders that face a liquidity shock are more likely to be asset sellers and a high counterparty risk in transactions, securities that trade on exchanges with higher counterparty risk are likely to trade at a relative discount.

To illustrate this point consider a simplified model with $N$ risk-neutral traders in a competitive market in which each trader, $n$, has a random endowment, $Q_{i, n}$, of assets, $i$, each asset trades at a price $P_{i}$, and the total trader's portfolio value, $A_{n}$, is the aggregated value of all assets so that

$$
A_{n}=\sum_{i} Q_{i, n} P_{i, n}
$$

Let each trader also owe a fixed value of notional debt, $D_{n}$, such that if $A_{n}<D_{n}$, the trader is forced to liquidate all assets. If this forced liquidation occurs, then all trading counterparties and debt holders recover a fixed percent, $R_{n}$, of the total liabilities owed, which is just

$$
R_{n}=\frac{A_{n}}{D_{n}+S_{n}}
$$

where $S_{n}$ is the total amount owed by trader $n$ for outstanding trades after settlement. Buyers of securities do not know the value of the trading portfolio of their counterparties but do know the distributional properties of the endowment shock. Since markets are competitive and agents are risk neutral, the value of any security for buyers is equal to

$$
P_{i}=P_{i}^{\text {Fun }}\left(1-E_{n}\left[\left(1-R_{i}\right)\right]\right),
$$

where $P_{i}^{\text {Fun }}$ is the fundamental value of the security, in the absence of counterparty risk, ${ }^{24}$ and $E_{n}\left[\left(1-R_{i}\right)\right]$ is the expected losses due to counterparty risk across all traders in asset $i$. As long as some positive number of traders are forced to sell assets, then buyers will rationally discount the value of these securities. Since markets are competitive and subject to market-clearing conditions (i.e., assets are in short-run fixed net supply),

\footnotetext{
${ }^{24}$ Or other market trading costs, which for simplicity are excluded from this model.
} 
traders sell only if forced to liquidate and all buyers of these securities are unconstrained (no counterparty risk) traders. Only those traders forced to liquidate have recoveries less than 100 percent, so counterparty risk induces a discounted price in equilibrium. As the expected recovery falls, this premium rises. So in times of distress, when endowment dispersion is large, this premium should be large, while in less turbulent times it could be close to zero. It also means that if the same security is traded in two markets with differing levels of counterparty risk, it should trade at a discount on whichever exchange has the highest counterparty risk, even in the presence of active arbitrageurs on both exchanges. Just as in the case of other trading costs (except bid-ask spreads, trading fees) considered in models of market illiquidity by a number of previous authors including Amihud and Mendelson (1991), Acharya and Pedersen (2005), and Garleanu and Pedersen (2011), counterparty risk costs are asymmetrically borne by buyers and sellers, leading to predictable price changes in equilibrium. ${ }^{25}$

\section{B. Baseline Empirical Methodology}

The expected change in the NYSE price after the introduction of centralized clearing equals the change in the stock price caused by changes in the fundamental value minus changes in the expected market illiquidity and counterparty risk premia or, equivalently,

$$
E\left[\Delta P_{i, \mathrm{NYSE}}\right]=E\left[\Delta P_{i}^{F u n}\right]-E\left[\Delta P_{i, t, \mathrm{NYSE}}^{\mathrm{MkLLq}}\right]-E\left[\Delta P_{i, t, \mathrm{NYSE}}^{C P}\right] .
$$

If we assume that the expected market illiquidity premium is unaffected by the introduction of multilateral netting, an assumption that we will examine later, we can rewrite (3) as

$$
E\left[\Delta P_{i, \mathrm{NYSE}}\right]=E\left[\Delta P_{i}^{F u n}\right]-E\left[\Delta P_{i, t, \mathrm{NYSE}}^{C P}\right],
$$

where expected changes in price are driven by changes in expected fundamental value and the counterparty risk premium.

We are interested in estimating $E\left[\Delta P_{i, t, \mathrm{NYSE}}^{C P}\right]$, the change in the counterparty risk premium caused by the introduction of multilateral netting. If the introduction of the clearinghouse were exogenous, we could simply estimate a panel regression

$$
P_{i, t, \mathrm{NYSE}}=\alpha_{i}+D 1_{\{\mathrm{clear}, i, t\}}+\epsilon_{i, t},
$$

\footnotetext{
${ }^{25}$ As in Acharya and Pedersen (2005), the fact that equities are in positive net supply can also lead to price discounts as trading costs rise, even without asymmetries between buyers and sellers. A precise investigation of whether price discounts in this setting are driven by the positive net supply of securities or asymmetric counterparty risk is beyond the scope of this paper. In either case, though, a rise in counterparty risk on a given exchange should lead to a predictable price discount, in expectation.
} 
where $1_{\{\text {clear }, i t\}}$ is a dummy variable indicating when a stock starts being included in centralized clearing and $D$ is the average treatment effect of centralized clearing on the stock price. The problem, as shown in equation (4), is that if the introduction of centralized clearing coincides with changes in the fundamental value of the firm, omitted variables rather than counterparty risk changes could be driving results. Here, for example, the introduction of centralized clearing on the NYSE was driven, in part, by financial panics in the early 1890s (McSherry and Wilson 2013). Without an alternative identification strategy, it would be impossible to identify the effect of the introduction of the NYSE clearinghouse. Fortunately, our historical experiment provides a unique opportunity to do exactly this.

Ideally, to determine the effect of centralized clearing on counterparty risk, we would have prices for identical securities that do not experience any change in counterparty risk to control for changes in asset value not related to clearing. Fortunately, such securities exist. During the late nineteenth and early twentieth centuries, stocks were dual-listed on the NYSE and CSE. Further, there was no change in the trading environment at the CSE when the NYSE introduced its clearinghouse. For the CSE price we have

$$
P_{i, t, \mathrm{CSE}}=P_{i, t}^{F u n}-P_{i, t, \mathrm{CSE}}^{M k L q}-P_{i, t, \mathrm{CSE}}^{C P}+\epsilon_{i, t, \mathrm{CSE}}
$$

Using the CSE prices as a control, the difference in prices between the dual-listed securities is

$$
\begin{aligned}
P_{i, t, \mathrm{NYSE}}-P_{i, t, \mathrm{CSE}}= & P_{i, \mathrm{CSE}}^{M k t L q}-P_{i, \mathrm{NYSE}}^{M k L q}+P_{i, t, \mathrm{CSE}}^{C P}-P_{i, t, \mathrm{NYSE}}^{C P} \\
& +\epsilon_{i, t, \mathrm{NYSE}}-\epsilon_{i, t, \mathrm{CSE}}
\end{aligned}
$$

where the fundamental value drops out of the equation. Then looking at the difference after the introduction of centralized clearing, we have

$$
E\left[\Delta P_{i, \mathrm{NYSE}}\right]-E\left[\Delta P_{i, \mathrm{CSE}}\right]=E\left[\Delta P_{i, t, \mathrm{CSE}}^{M k L q}\right]-E\left[\Delta P_{i, t, \mathrm{NYSE}}^{M k L q}\right]-E\left[\Delta P_{i, t, \mathrm{NYSE}}^{C P}\right],
$$

so that the difference-in-differences between the expected prices on the two exchanges is caused by changes in the relative market illiquidity premium and changes in the counterparty risk premium on the NYSE. If there is no change in centralized clearing on the CSE, then the expected change in the CSE counterparty risk premium, $E\left[\Delta P_{i, t, \mathrm{CSE}}^{C P}\right]$, is zero and drops out of equation (8).

If the difference in expected market liquidity between the two exchanges is the same before and after the introduction of centralized clearing on the NYSE, ${ }^{26}$ then the difference-in-difference in prices can be written as

\footnotetext{
${ }^{26}$ It is worth noting that even if the exchanges have differing levels of market liquidity prior to the introduction of centralized clearing on the NYSE, the difference-in-difference
} 


$$
\Delta E\left[P_{i, t, \mathrm{NYSE}}\right]-\Delta E\left[P_{i, t, \mathrm{CSE}}\right]=-E\left[\Delta P_{i, t, \mathrm{NYSE}}^{C P}\right],
$$

which is a causal estimate of the effect of centralized clearing on the counterparty risk premium. Formally, our baseline empirical specification is

$$
\hat{P}_{i, t, \mathrm{NYSE}}-\hat{P}_{i, t, \mathrm{CSE}}=\alpha_{i}+D 1_{\{\text {clear }, i, t\}}+X_{i, t}^{\prime} \beta+\epsilon_{i, t},
$$

where $\hat{P}_{i, t, \mathrm{CSE}}$ and $\hat{P}_{i, t, \mathrm{NYSE}}$ are the normalized closing prices on the NYSE and CSE.

Throughout our analysis, we consider two normalizations for price: (1) dividing by the average closing prices on both exchanges and (2) dividing by the NYSE bid-ask spread. The former is natural since it is the percentage premium or discount an investor would require for buying the same stock on the NYSE relative to the CSE. The latter is also intuitive since it adjusts for the relative cost of trading the security and indicates how many bid-ask spreads the price on the NYSE deviates from the same security on the CSE. As discussed above, $1_{\{c l e a r, i, t\}}$ is a dummy variable indicating when a stock starts centralized clearing and $D$ is the average treatment effect of centralized clearing on the relative normalized stock prices. In addition, we include stock-specific time-varying controls, $X_{i, t}$, including bid-ask spreads and volumes.

It is important to note that in this core specification, we are implicitly assuming that there are no spillovers in counterparty risk reduction when only a fraction of NYSE stocks join the clearinghouse. That is, it is likely that counterparty risk for stocks not yet cleared will fall once a sufficient fraction of NYSE stock volume is cleared. We investigate such spillover effects in Section IV.D.

\section{Price Volatility Induced by Counterparty Risk}

Because counterparty risk was driven by the costs of financing overnight positions, we expect the counterparty risk premium to be small during periods of calm but increase dramatically during times of financial market distress. Because the cost of financing overnight positions was likely much less after the onset of multilateral netting, its introduction may have significantly reduced or eliminated the impact of short-term financing shocks on NYSE stocks. Hence, interest rate shocks should not re-

framework just relies on the same relative changes in liquidity following the introduction of the NYSE clearinghouse. A concern could be that trading might migrate to the NYSE since the clearinghouse improved the NYSE trading environment, which might also result in a degradation of trading conditions on the CSE. We show, however, that trading volumes, spreads, and percentage of days with at least one odd-lot trade on both exchanges changed in a parallel fashion after the NYSE clearinghouse was introduced. 
duce stock prices on the NYSE relative to the CSE after the establishment of a clearinghouse. ${ }^{27}$ We formalize this test by interacting call loan rates with the clearinghouse dummy to yield the following specification:

$$
\begin{aligned}
\hat{P}_{i, t, \mathrm{NYSE}}-\hat{P}_{i, t, \mathrm{CSE}}= & \alpha_{i}+D 1_{\{\text {clear }, i t\}}+D_{2} C_{t} \times 1_{\{\text {clear }, i t\}}+\phi C_{t} \\
& +X_{i, t}{ }^{\prime} \beta+\epsilon_{i, t},
\end{aligned}
$$

where $C_{t}$ is the call loan rate, $\phi$ is the estimated effect of call loan rate spikes on NYSE relative prices before clearing, and $D_{2}$ is the estimated effect of the introduction of centralized clearing on call loan rate sensitivity.

Before the introduction of the NYSE clearinghouse, interest rate volatility and the volatility of the NYSE-CSE price spread will move in response to fluctuations in counterparty risk. If we consider the change in volatility of the price difference, instead of the expectation, and make slightly stronger assumptions (relative to those needed to arrive at eq. [9]), ${ }^{28}$ then we can rewrite equation (9) as

$$
\Delta \sigma\left[P_{i, t, \mathrm{NYSE}}-P_{i, t, \mathrm{CSE}}\right]=\Delta \sigma\left[P_{i, t, \mathrm{NYSE}}^{C P}\right] .
$$

Equation (12) indicates that the change in the volatility of the price premium provides an estimate of the change in counterparty risk volatility caused by clearing. We estimate the volatility of price spreads by taking the absolute value of the price differences between the exchanges on each date normalized by the average closing price on the exchanges and then scaling by a constant to generate an estimate for the volatility. ${ }^{29}$ In our robustness analysis, we also consider the volatility estimator using the ratio of the high and low prices on each exchange presented in Parkinson (1980).

\footnotetext{
${ }^{27}$ One might wonder whether the onset of multilateral netting might also affect the magnitude of interest rate shocks. Although this is theoretically a possibility, anecdotal evidence (see Meeker 1922) suggests that the main driver of shocks to the call loan rate was the commercial paper market. Indeed Bernstein et al. (2010) find that the correlation between the commercial paper rate and the call loan rate was over 90 percent during our sample period.

28 Previously we assumed no changes in the relative market illiquidity premium. In this case we need to assume no changes in the volatility of the market illiquidity premium; but in addition we have to assume no change in the volatility of relative market microstructure noise or in the covariance between the counterparty risk premia, market illiquidity premia, and/or market microstructure premia.

${ }^{29}$ If $X \sim N(\mu, \sigma)$, then the absolute value of $X$ is distributed folded-normally. Then if the expected normalized price difference is sufficiently small relative to the volatility, then the volatility is proportional to the absolute value of $X$. In particular, $\sigma \approx \sqrt{\pi / 2} E[|X|]$. In our analysis the expected normalized price difference is significantly smaller than the volatility, so our estimated volatility using this approximation is within approximately $1 \mathrm{bp}$ of the change in volatility accounting for any changes in the mean normalized price difference. For a complete discussion of the estimator and its properties, see online app. C.
} 


\section{Counterparty Risk and Contagion}

Counterparty risk can be divided into two parts: contagion risk and direct counterparty risk. Contagion risk is higher for an asset when a broker is more likely to default on other positions, starting a cascade that results in default on a trade for that asset. When other stocks start to clear, contagion risk is smaller, even if the asset is traded through a clearinghouse. We define the reduction in direct counterparty risk as the direct effect of a stock centrally clearing after accounting for any contagion risk reduction. One of the benefits of analyzing the introduction of centralized clearing on the NYSE is that centralized clearing was introduced in stages. Using prices on the CSE as a control again, we can decompose the volatility induced by counterparty risk by estimating the following model:

$$
\left|\hat{P}_{i, t, \mathrm{NYSE}}-\hat{P}_{i, t, \mathrm{CSE}}\right|=\alpha_{i}+D 1_{\{\text {clear }, i, t\}}+\gamma \operatorname{PercClear}_{i, t}+X_{i, t}{ }^{\prime} \beta+\epsilon_{i, t},
$$

where PercClear ${ }_{i, t}$ is the percentage of stocks already clearing. ${ }^{30}$ We also include a dummy for the stock that is centralized clearing, which allows a natural interpretation for $D$ as the change in counterparty risk caused by direct counterparty risk, while $\gamma$ is the percent caused by a change in contagion risk. ${ }^{31}$ Since the breakdown of these two types of risk depends on how connected traders of those securities are to the network of traders, we would expect these to vary across securities. In particular, we might expect securities with traders who are more exposed to traders in the rest of the network, such as large firms with high-volume securities, to be more exposed to contagion risk. ${ }^{32}$

\section{Results}

We first compare the sign and volatility of the counterparty risk premium before and after the introduction of centralized clearing on the NYSE. To do so, we reconsider equation (7):

\footnotetext{
${ }^{30}$ We consider weights both by dollar sales and equally but focus on dollar sales for our primary analysis since it is more representative of the actual volume of trading of the security.

${ }^{31}$ In this setting even if inclusion in the clearinghouse was anticipated, prices would not adjust in response, since arbitrageurs would still be exposed to any counterparty risk in transacting to try to "take advantage" of the price discount any day prior to the actual inclusion of the stock in the list of centrally cleared securities.

${ }^{32}$ While it seems intuitive that high trading volumes would seem to suggest more interconnected traders, without specifics on the exact nature of the network, it is impossible to know with certainty which security types are most exposed to contagion. It becomes an empirical question, based on how $D$ in eq. (13) varies with security trading volume.
} 


$$
\begin{aligned}
P_{i, t, \mathrm{NYSE}}-P_{i, t, \mathrm{CSE}}= & P_{i, \mathrm{CSE}}^{M k L q}-P_{i, \mathrm{NYSE}}^{M k t L}+P_{i, t, \mathrm{CSE}}^{C P}-P_{i, t, \mathrm{NYSE}}^{C P} \\
& +\epsilon_{i, t, \mathrm{NYSE}}-\epsilon_{i, t, \mathrm{CSE}} .
\end{aligned}
$$

Because the NYSE is more liquid than the CSE (Brown et al. [2008] and table 1 summary statistics), the price discount due to illiquidity should be smaller on the NYSE: $E\left[P_{i, \mathrm{CSE}}^{M k L q}-P_{i, \mathrm{NYSE}}^{M k L q}\right]>0$. Therefore, when counterparty risk is small, stocks should trade at a premium on the NYSE relative to the CSE. In times of financial market crisis before stocks are cleared on the NYSE, stocks on the NYSE might well trade at a discount instead because during crises, counterparty risk might be much larger on the NYSE than on the CSE. Before the introduction of centralized clearing on the NYSE then, stocks trade at a discount on the NYSE when the counterparty risk premium is high and at a slight premium otherwise. If the introduction of centralized clearing on the NYSE eliminates (or substantially reduces) counterparty risk there, equation (7) implies that after the onset of clearing, prices on the Big Board should be consistently higher than those on the CSE.

In figure 4 we plot the average for all Dow stocks of the 12-month moving average of the price on the NYSE minus the price on the CSE normalized by the NYSE bid-ask spread. Prior to the introduction of centralized clearing, this price difference is highly volatile; but after the introduction of clearing, stocks on the NYSE consistently trade at a premium. In table 2 , we estimate equation (10) to show that the introduction of centralized clearing on the NYSE reduces the average counterparty risk premium by 24 bp or 0.73 NYSE bid-ask spreads. ${ }^{33}$ NYSE prices are $9 \mathrm{bp}$ lower on average than CSE prices prior to clearing but $15 \mathrm{bp}$ higher afterward. This result is robust to including stock-specific timevarying market liquidity controls on the NYSE and CSE, including the bidask spread on the NYSE, the dollar trading volume on the NYSE, and the dollar trading volume on the CSE. The result is not robust, however, to not using the CSE as a control. ${ }^{34}$ This highlights the importance of using identical securities traded on the CSE to control for the changing macroeconomic environment.

The 24 bp reduction is a substantial decline in the counterparty risk premium. This estimate for the reduction in the counterparty risk

${ }^{33}$ On the basis of statistics in McSherry et al. (2017), it appears that as a percentage of total NYSE trading volume, initial reported losses from broker insolvencies fall approximately $42 \mathrm{bp}$ in the period after the introduction of a clearinghouse. If we account for subsequent partial recovery of those losses, this appears consistent in magnitude with the estimates we obtain for the fall in counterparty risk premium coming from the decline in expected losses with our formal difference-in-difference analysis of prices. The specification includes firm fixed effects, clustering standard errors at the stock level, and using identical securities on the CSE as a control.

${ }_{34}$ These results are available from the authors on request. 

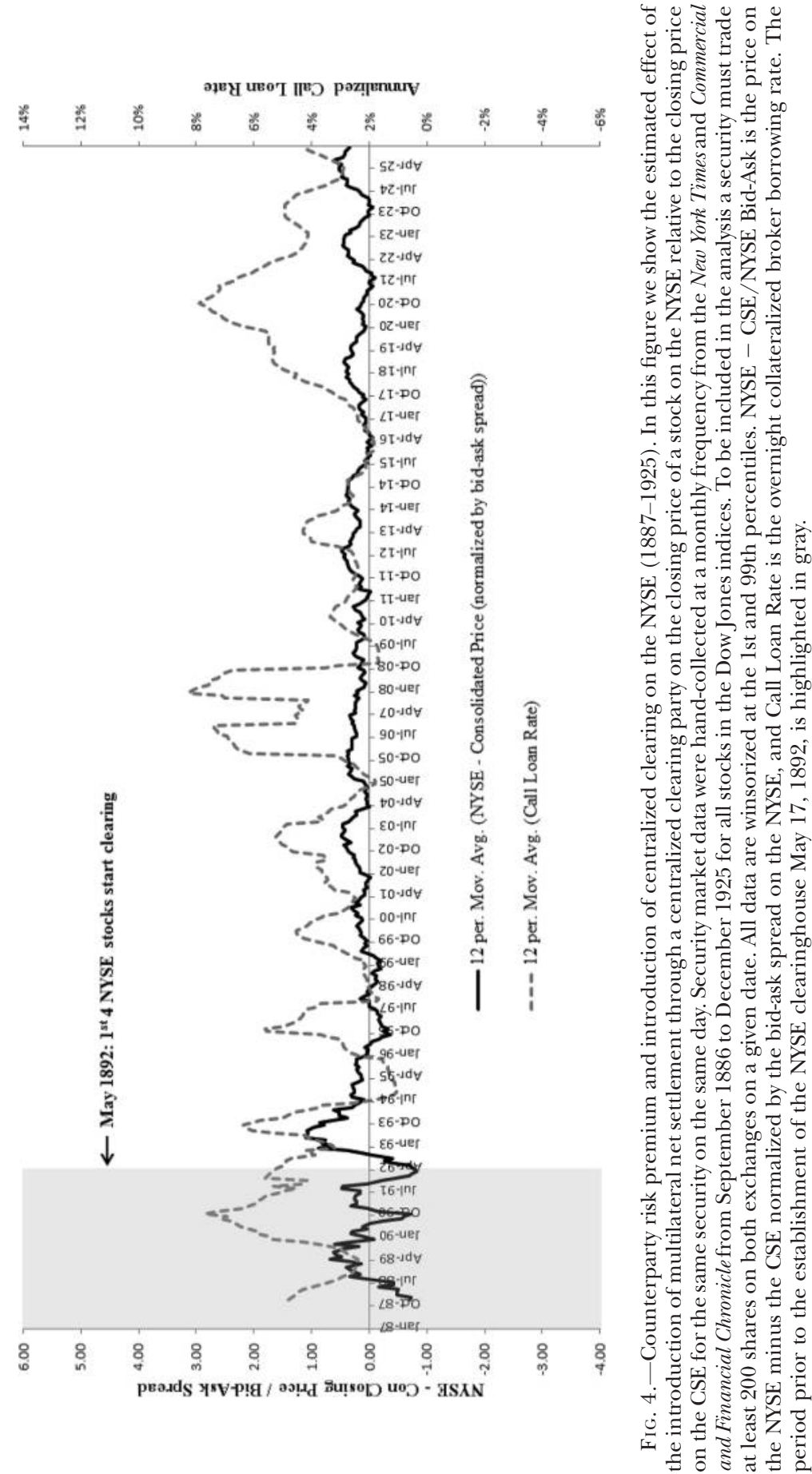
TABLE 2

Price Deviations and Establishment of NYSE Clearinghouse

\begin{tabular}{|c|c|c|c|c|c|c|}
\hline & \multicolumn{6}{|c|}{ DEPENDENT VARIABLE } \\
\hline & $\begin{array}{l}\text { NYSE - } \\
\text { CSE/ } \\
\text { Close }(\%) \\
(1)\end{array}$ & $\begin{array}{c}\text { NYSE - } \\
\text { CSE/NYSE } \\
\text { Bid-Ask } \\
(2)\end{array}$ & $\begin{array}{c}\text { NYSE - } \\
\text { CSE/ } \\
\text { Close (\%) } \\
(3)\end{array}$ & $\begin{array}{c}\text { NYSE - } \\
\text { CSE/ } \\
\text { Close }(\%) \\
(4)\end{array}$ & $\begin{array}{c}\text { NYSE - } \\
\text { CSE/Close } \\
(\%) \\
(5)\end{array}$ & $\begin{array}{c}\text { NYSE - } \\
\text { CSE/ } \\
\text { Close }(\%) \\
(6)\end{array}$ \\
\hline Clearinghouse & $\begin{array}{l}.237 * * * \\
(.062)\end{array}$ & $\begin{array}{l}.733 * * * \\
(.126)\end{array}$ & $\begin{array}{l}.234 * * * \\
(.061)\end{array}$ & $\begin{array}{l}.230 * * * \\
(.061)\end{array}$ & $\begin{array}{l}.122 * \\
(.068)\end{array}$ & \\
\hline Call loan rate & & & & $\begin{array}{c}-.0029 \\
(.0019)\end{array}$ & $\begin{array}{c}-.0217 * * * \\
(.0055)\end{array}$ & $\begin{array}{l}.0022 \\
(.0017)\end{array}$ \\
\hline $\begin{array}{l}\text { Call loan rate } \times \\
\text { clearinghouse }\end{array}$ & & & & & $\begin{array}{l}.0247 * * * \\
(.0058)\end{array}$ & \\
\hline Constant & $\begin{array}{c}-.094 * * \\
(.040)\end{array}$ & $\begin{array}{c}-.295 * * * \\
(.082)\end{array}$ & $\begin{array}{c}-.107 * * \\
(.045)\end{array}$ & $\begin{array}{c}-.093 * \\
(.048)\end{array}$ & $\begin{array}{c}-.0083 \\
(.0055)\end{array}$ & $\begin{array}{c}-.0062 \\
(.023)\end{array}$ \\
\hline $\begin{array}{l}\text { Security fixed } \\
\text { effects }\end{array}$ & Yes & Yes & Yes & Yes & Yes & Yes \\
\hline $\begin{array}{l}\text { Liquidity } \\
\text { controls } \\
\text { Only clearing- }\end{array}$ & No & No & Yes & Yes & Yes & Yes \\
\hline house & No & No & No & No & No & Yes \\
\hline No. clusters & 90 & 90 & 90 & 90 & 90 & 51 \\
\hline Observations & 5,997 & 5,984 & 5,994 & 5,994 & 5,994 & 3,904 \\
\hline Adjusted $R^{2}$ & .0086 & .0056 & .0104 & .0105 & .0138 & .0326 \\
\hline
\end{tabular}

Note.-Following econometric specifications (9) and (10), in this table we show the estimated effect of the introduction of multilateral net settlement through a centralized clearing party on the closing price of a stock on the NYSE relative to the closing price on the CSE for the same security on the same day. Security market data were hand-collected at a monthly frequency from the New York Times and Commercial and Financial Chronicle from September 1886 to December 1925 for all stocks in the Dow Jones indices. To be included in the analysis a security must trade at least 200 shares on both exchanges on a given date. All data are winsorized at the 1st and 99th percentiles. In col. 1, NYSE - CSE/Close is the price on the NYSE minus the CSE normalized by the average closing price on both exchanges. Clearinghouse is a stock-specific dummy variable that equals one if a stock is cleared on the NYSE. In col. 2, NYSE - CSE/NYSE Bid-Ask is the left-hand-side variable and is the price on the NYSE minus the CSE normalized by the bid-ask spread on the NYSE. Col. 3 shows the results including stock-specific time-varying market liquidity controls on the NYSE and CSE. These include the bid-ask spread on the NYSE, the dollar trading volume on the NYSE, and the dollar trading volume on the CSE. Col. 4 shows the results after including call loan rate $(\%)$, the overnight collateralized borrowing rate. Col. 5 includes an interaction term between the clearinghouse dummy variable and the call loan rate $(\%)$ as described in specification (10). Col. 6 repeats the analysis in col. 4 but restricting the sample to only stocks already clearing. All specifications are run with security-level fixed effects, and errors are clustered at the security level.

$* p<10$ percent.

$* * \quad p<5$ percent.

$* * * \quad p<1$ percent.

premium is on the high end of those obtained in analyses of modern counterparty risk in the credit derivative markets. Arora et al. (2012) note that estimates of the size of the counterparty risk premium for CDSs in the modern period range from 7 to $20 \mathrm{bp}$. If we scaled the effects to the size of the modern NYSE, this would equate to approximately a $\$ 40$ billion in- 
crease in value caused by the reduction in counterparty risk from the introduction of a clearinghouse. ${ }^{35}$

We next investigate the drivers of the counterparty risk premium on the NYSE. Because brokers had to fund substantial levered positions overnight, shocks to overnight borrowing rates were an important determinant of counterparty risk prior to centralized clearing on the NYSE. In figure 4, we also plot the 12-month moving average of the broker's call loan rate. As expected, prior to the introduction of centralized clearing on the NYSE, stocks tend to trade at a discount relative to identical securities on the CSE during periods when the call loan rate is high and at a premium when call loan rates are low. In table 2, we formally investigate whether high call loan rates are associated with price discounts on the NYSE. We find that call loan rates appear unrelated to changes in the NYSE-CSE relative prices after the introduction of clearing. Column 4 shows that there is not a statistically significant relationship between the normalized difference in NYSE and CSE prices and the call loan rate for the full sample period. The reason is that the relationship is masked by the change in the relationship between call loan rates and counterparty risk after the introduction of clearing. In column 5 , we estimate equation (10). We find that before the introduction of clearing, a one standard deviation increase in the call loan rate in the pre-clearinghouse period is associated with approximately an 8 bp reduction in the price on the NYSE relative to the CSE. ${ }^{36}$ The effect is not statistically significant, however, after the introduction of clearing. As expected, we do not find evidence of a relationship between call loan rates and our normalized measure of relative NYSE-CSE prices after a stock joins the clearinghouse (see col. 6). The result is consistent with the introduction of centralized clearing mitigating the impact of funding shocks on counterparty risk for NYSE stocks. In table A5 we rerun the analysis, but instead look at the effect of commercial paper rates on the premium before and after the introduction of clearing. Again we find that a rise in funding costs reduces the value of the NYSE stocks but that this is no longer true after the introduction of the NYSE clearinghouse. These results hold for both rates, though they are stronger for call loan rates, when both measures of funding costs are included. ${ }^{37}$

\footnotetext{
35 The market cap of $\$ 16.6$ trillion for the NYSE is taken from the NYSE website as of August 2014.

${ }_{36}$ We find that a 1 percentage point increase in the call loan rate is associated with more than a 2 bp reduction in the relative price of NYSE stocks that also trade on the CSE, and the standard deviation of the call loan rate was 3.7 percent before the introduction of the NYSE clearinghouse.

${ }_{37}$ These results are consistent with a relationship between counterparty risk and costs of borrowing. As noted by Moen and Tallman (2003), call loan rates were funds borrowed on margin that were callable on notice within the day, but 95 percent of loans were rolled over with substituted stock collateral. These loans were oftentimes used to cover capital short-
} 
After the introduction of centralized clearing on the NYSE, shocks to the call loan rate no longer affect prices on the NYSE relative to those on the CSE. Call loan rates continue to be volatile, however (see fig. 4). Therefore, we would expect a decline in the volatility of NYSE returns given the reduction in the volatility of the counterparty risk premium. In figures 5 and 6 , we observe a dramatic decline in the volatility of the counterparty risk premium after the introduction of clearing that stays low for more than 30 years after the NYSE clearinghouse is introduced. ${ }^{38}$ In table 3 , we show that the monthly average absolute price difference of the NYSE relative price falls 20 bp or 0.93 NYSE bid-ask spreads after the introduction of clearing. These results are robust to including stockspecific time-varying market liquidity controls such as bid-ask spreads on the NYSE and CSE and the broker call loan rate interacted with a postclearinghouse dummy. As we discussed previously, the results represent a lower bound on the effects of centralized clearing since other stocks centrally clearing reduce the counterparty risk for non-centrally cleared stocks, reducing the estimated effect of centralized clearing on counterparty risk. Since most stocks were already centrally clearing by the end of 1893 , we include a post-1893 dummy variable instead of the post-clearinghouse dummy. After 1893, the average absolute price deviation fell by $40 \mathrm{bp}$. Scaling the absolute values by $\sqrt{\pi / 2}$ to obtain estimates of the change in standard deviation, we get a daily counterparty risk volatility of $50 \mathrm{bp}$ conditional on a transaction. ${ }^{39}$ Since the average annualized volatility for stocks on the Dow Jones was 29.6 percent, the daily fundamental volatility was 1.86 percent, which means that conditional on executing a trade, the $t+1$ settlement risk induced was as much as 26.9 percent of the total fundamental risk experienced over that same time period.

In table 4, we attempt to distinguish the effects of contagion risk through network spillovers from the effects of direct counterparty risk. We first include monthly date fixed effects and find that the point estimate for the effect of centralized clearing on the counterparty risk premium volatility

falls following failed settlements. In this way these rates were not only influenced by aggregate fluctuations in short-term borrowing rates but also likely to have a direct relationship with counterparty risk on the exchange. Therefore, our results are largely consistent with clearinghouses not causing or serving as a panacea for macroeconomic financial crises, but rather that the absence of a clearinghouse can exacerbate a crisis by increasing market turbulence and contagion risk.

38 The stability of the decline in the more than 30 years, through multiple periods of economic turbulence, after the introduction of the NYSE clearinghouse should alleviate concerns regarding any differences in market liquidity, participants, specialization, or settlement period on the two exchanges, since as we will show there is little evidence of a dramatic change in any of these at the same time the NYSE clearinghouse is introduced.

${ }^{39}$ If, instead of assuming normality, we bootstrap from the original residual distribution, we obtain similar estimates. Since these results are similar to those obtained under normality and those under normality are slightly more conservative, we focus primarily on that interpretation. We thank Neil Shephard for the suggestion. 


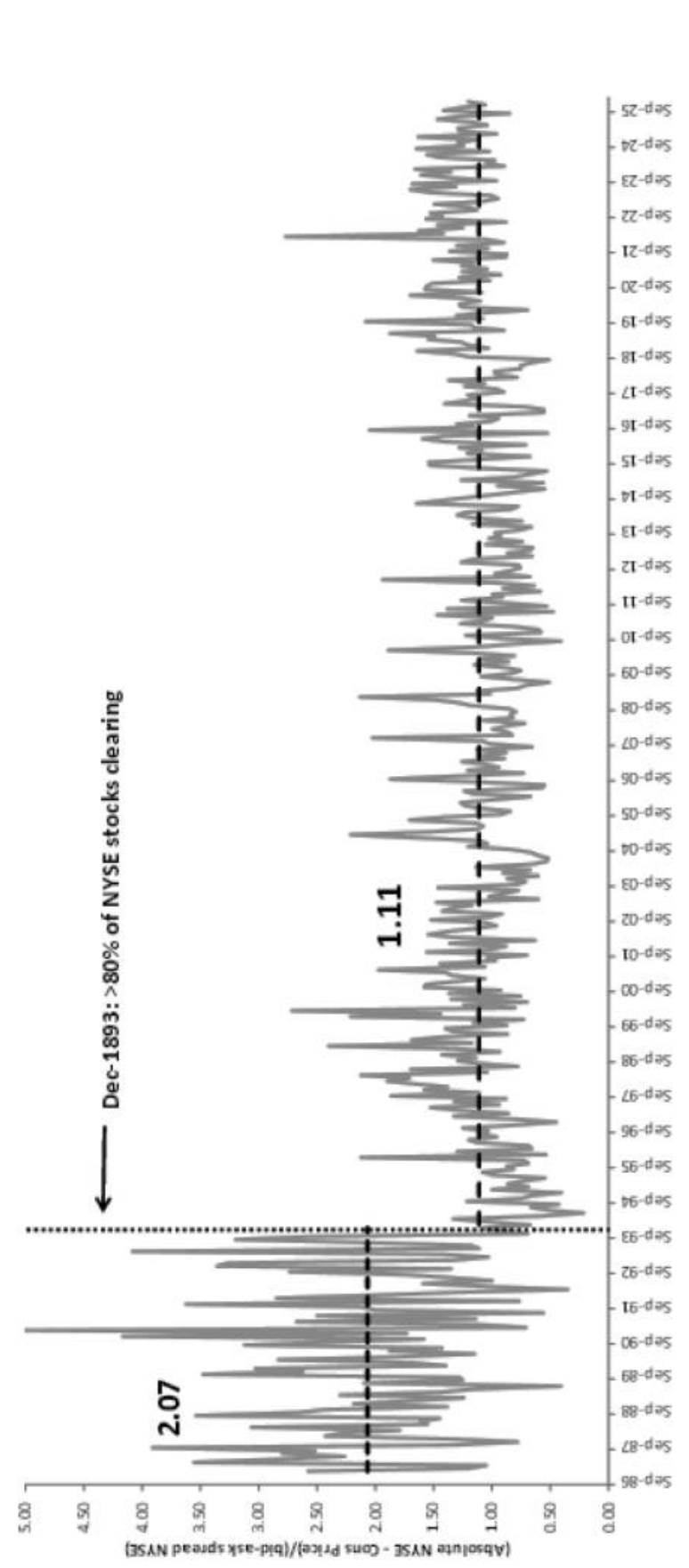

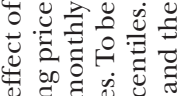

:

은

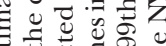

낭

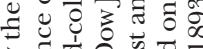

言记

象政

政

:

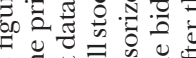

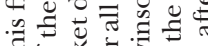

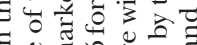

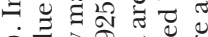

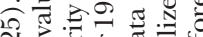

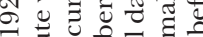

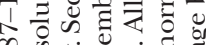

$\infty$ है

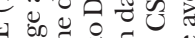

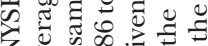

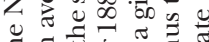

Ð

‡ี

क क तै

పె

U.

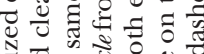

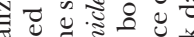

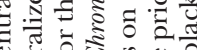

엉 \& \&

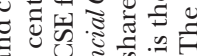

ส $\pi$ है क

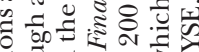

ప

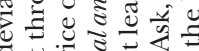

氙氞

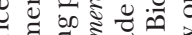

ป气

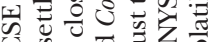

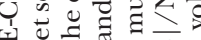

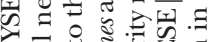

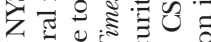

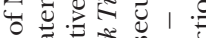

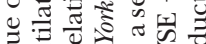

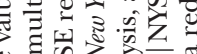

¿

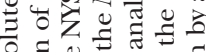

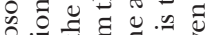

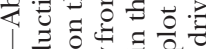

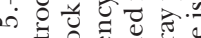

ن. $\Xi$ 过

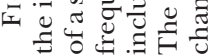




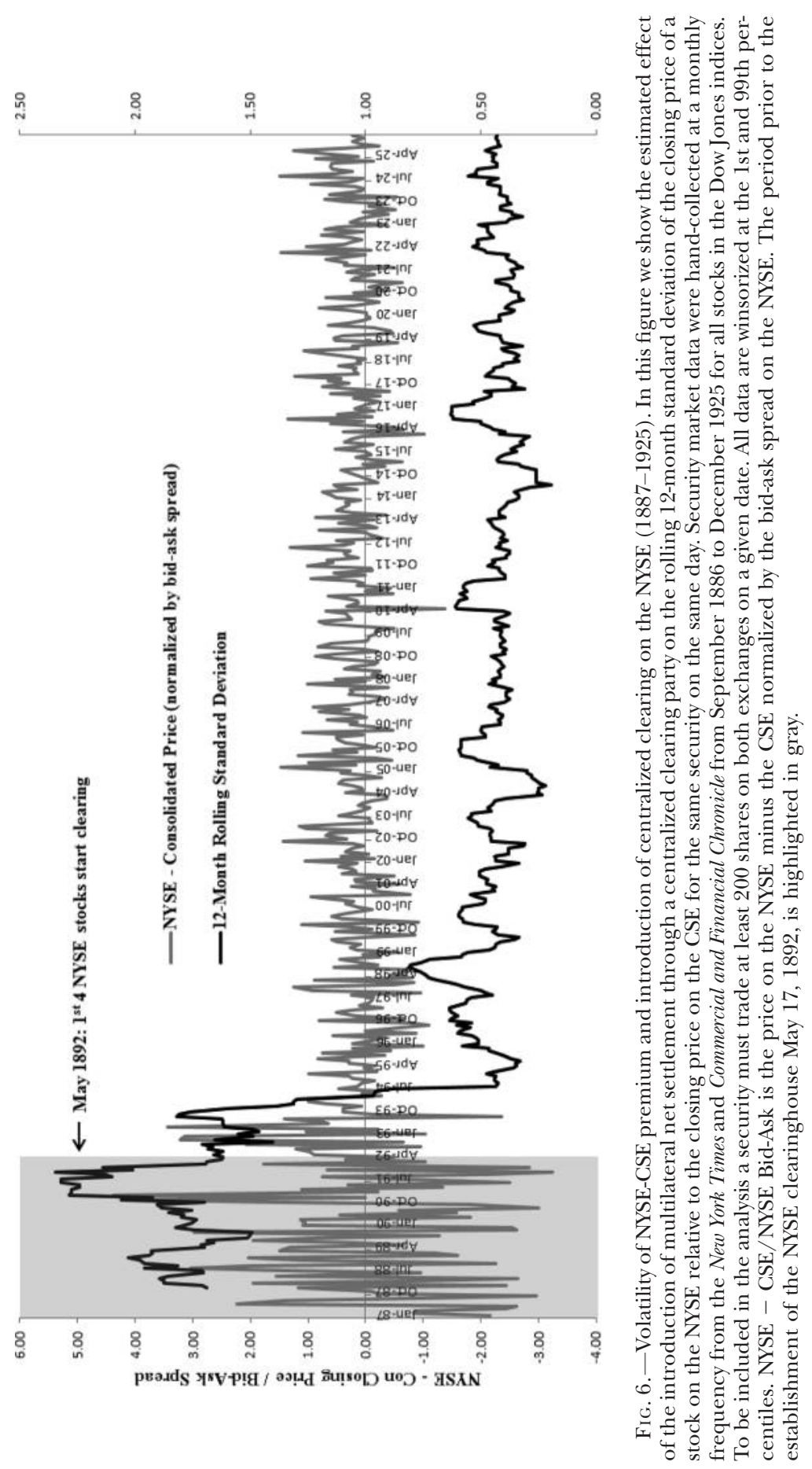


TABLE 3

Counterparty Risk Premium and Establishment of the NYSE Glearinghouse

\begin{tabular}{|c|c|c|c|c|c|c|}
\hline & \multicolumn{6}{|c|}{ Dependent Variable } \\
\hline & $\begin{array}{c}\mid \text { NYSE - } \\
\text { CSE } \mid / \\
\text { Close }(\%) \\
(1)\end{array}$ & $\begin{array}{c}\mid \text { NYSE - } \\
\text { CSE } \mid / \text { NYSE } \\
\text { Bid-Ask } \\
(2)\end{array}$ & $\begin{array}{c}\mid \mathrm{NYSE}- \\
\mathrm{CSE} \mid / \\
\text { Close }(\%) \\
(3)\end{array}$ & $\begin{array}{c}\mid \text { NYSE - } \\
\text { CSE } \mid / \\
\text { Close }(\%) \\
(4)\end{array}$ & $\begin{array}{c}\mid \text { NYSE - } \\
\text { CSE } \mid / \\
\text { Close }(\%) \\
(5)\end{array}$ & $\begin{array}{c}\mid \text { NYSE - } \\
\text { CSE } \mid / \\
\text { Close (\%) } \\
(6)\end{array}$ \\
\hline Clearinghouse & $\begin{array}{c}-.204 * * \\
(.105)\end{array}$ & $\begin{array}{c}-.929 * * * \\
(.323)\end{array}$ & $\begin{array}{c}-.207 * * * \\
(.082)\end{array}$ & $\begin{array}{c}-.174 * * \\
(.089)\end{array}$ & & \\
\hline Post-1893 & & & & & & $\begin{array}{c}-.399 * * * \\
(.077)\end{array}$ \\
\hline Call loan rate & & & & $\begin{array}{c}.0081 * \\
(.0046)\end{array}$ & $\begin{array}{c}.0009 \\
(.0015)\end{array}$ & \\
\hline $\begin{array}{l}\text { Call loan rate } \times \\
\text { clearing- } \\
\text { house }\end{array}$ & & & & $\begin{array}{c}-.0067 \\
(.0049)\end{array}$ & & \\
\hline Constant & $\begin{array}{l}.544^{* * * *} \\
(.069)\end{array}$ & $\begin{array}{l}1.840 * * * \\
(.210)\end{array}$ & $\begin{array}{l}.397 * * * \\
(.055)\end{array}$ & $\begin{array}{l}.360 * * * \\
(.064)\end{array}$ & $\begin{array}{l}.174 * * * \\
(.016)\end{array}$ & $\begin{array}{l}.557 * * * \\
(.0068)\end{array}$ \\
\hline $\begin{array}{l}\text { Security fixed } \\
\text { effects } \\
\text { Liquidity }\end{array}$ & Yes & Yes & Yes & Yes & Yes & Yes \\
\hline $\begin{array}{l}\text { controls } \\
\text { Only clearing- }\end{array}$ & No & No & Yes & Yes & Yes & Yes \\
\hline house & No & No & No & No & Yes & No \\
\hline No. clusters & 90 & 90 & 90 & 90 & 51 & 54 \\
\hline Observations & 5,997 & 5,984 & 5,994 & 5,994 & 3,904 & 4,314 \\
\hline Adjusted $R^{2}$ & .223 & .165 & .293 & .293 & .157 & .171 \\
\hline
\end{tabular}

Note.-Following econometric specifications (9), (10), and (11), in this table we show the estimated effect of the introduction of multilateral net settlement through a centralized clearing party on the volatility of the closing price of a stock on the NYSE relative to the closing price on the CSE for the same security on the same day by looking at the absolute value of the relative price differences. Security market data were hand-collected at a monthly frequency from the New York Times and Commercial and Financial Chronicle from September 1886 to December 1925 for all stocks in the Dow Jones indices. To be included in the analysis a security must trade at least 200 shares on both exchanges on a given date. All data are winsorized at the 1st and 99th percentiles. In col. 1, | NYSE - CSE $\mid$ /Close is the absolute value of the price on the NYSE relative to the CSE, normalized by the average closing price on both exchanges as a percentage. Clearinghouse is a stock-specific dummy variable that equals one if a stock is cleared on the NYSE. In col. 2, $\mid$ NYSE - CSE $\mid$ /NYSE Bid-Ask is the volatility of the price on the NYSE minus the CSE normalized by the bid-ask spread on the NYSE. Col. 3 shows the results with stock-specific time-varying market liquidity controls on the NYSE and CSE including the stock's bid-ask spread on the NYSE and dollar trading volume on the NYSE and the CSE. Col. 4 shows results after including call loan rate $(\%)$, the overnight collateralized borrowing rate, and an interaction term between the clearinghouse dummy variable and the call loan rate $(\%)$ as described in specification (10). Col. 5 repeats the analysis in col. 4 but restricting the sample to only stocks already clearing. Col. 6 includes a dummy, post-1893, that is equal to one for all securities centrally clearing after 1893 and zero prior to May 1892. All specifications are run with security-level fixed effects, and errors are clustered at the security level.

$$
\begin{aligned}
& * p<10 \text { percent. } \\
& * * p<5 \text { percent. } \\
& * * * p<1 \text { percent. }
\end{aligned}
$$


TABLE 4

Contagion (Indirect Counterparty) Risk

\begin{tabular}{|c|c|c|c|c|c|}
\hline & \multicolumn{5}{|c|}{ DEPENDENT VARIABLE } \\
\hline & $\begin{array}{c}\mid \text { NYSE - } \\
\text { CSE } \mid / \text { NYSE } \\
\text { Bid-Ask } \\
(1)\end{array}$ & $\begin{array}{l}\mid \mathrm{NYSE}- \\
\text { CSE } \mid / \\
\text { Close }(\%) \\
(2)\end{array}$ & $\begin{array}{c}\mid \text { NYSE - } \\
\text { CSE } \mid / \text { NYSE } \\
\text { Bid-Ask } \\
(3)\end{array}$ & $\begin{array}{c}\mid \text { NYSE - } \\
\text { CSE } \mid / \text { NYSE } \\
\text { Bid-Ask } \\
(4)\end{array}$ & $\begin{array}{l}\mid \mathrm{NYSE}- \\
\mathrm{CSE} \mid / \\
\text { Close }(\%) \\
(5)\end{array}$ \\
\hline$\%$ of Dow clearing & & & $\begin{array}{r}-.508 * \\
(.295)\end{array}$ & $\begin{array}{l}.328 \\
(.278)\end{array}$ & $\begin{array}{l}.020 \\
(.16)\end{array}$ \\
\hline Clearinghouse & $\begin{array}{r}-.370 \\
(.269)\end{array}$ & $\begin{array}{c}-.156^{*} \\
(.088)\end{array}$ & $\begin{array}{l}-.558 * * * \\
(.108)\end{array}$ & & \\
\hline $\begin{array}{l}\text { High volume } \\
\text { dummy } \times \% \text { of } \\
\text { Dow clearing }\end{array}$ & & & & $\begin{array}{l}-.772 * * \\
(.308)\end{array}$ & $\begin{array}{l}-.300^{* *} \\
(.137)\end{array}$ \\
\hline $\begin{array}{l}\text { High volume } \\
\text { dummy }\end{array}$ & & & & $\begin{array}{l}.538 * * \\
(.203)\end{array}$ & $\begin{array}{l}.201 * * \\
(.096)\end{array}$ \\
\hline Constant & $\begin{array}{l}1.830^{* * *} \\
(.119)\end{array}$ & $\begin{array}{l}.582 * * * \\
(.038)\end{array}$ & $\begin{array}{l}2.091 * * * \\
(.210)\end{array}$ & $\begin{array}{l}1.199 * * * \\
(.193)\end{array}$ & $\begin{array}{l}.329 * * * \\
(.098)\end{array}$ \\
\hline $\begin{array}{l}\text { Security fixed } \\
\text { effects }\end{array}$ & Yes & Yes & Yes & Yes & Yes \\
\hline Date fixed effects & Yes & Yes & No & No & No \\
\hline $\begin{array}{l}\text { Stock liquidity } \\
\text { controls }\end{array}$ & Yes & Yes & Yes & Yes & Yes \\
\hline $\begin{array}{l}\text { Only preclearing } \\
\text { stocks }\end{array}$ & No & No & No & Yes & Yes \\
\hline No. clusters & 90 & 90 & 90 & 50 & 50 \\
\hline Observations & 5,983 & 5,994 & 5,983 & 2,086 & 2,090 \\
\hline Adjusted $R^{2}$ & .236 & .326 & .186 & .332 & .398 \\
\hline
\end{tabular}

Note.-Following econometric specification (12), in this table we show the estimated effect of the introduction of multilateral net settlement through a centralized clearing party on the closing price of a stock on the NYSE relative to the closing price on the CSE for the same security on the same day broken out by contagion risk and direct counterparty risk. Security market data were hand-collected at a monthly frequency from the New York Times and Commercial and Financial Chronicle from September 1886 to December 1925 for all stocks in the Dow Jones indices. To be included in the analysis a security must trade at least 200 shares on both exchanges on a given date. All data are winsorized at the 1st and 99th percentiles. In col. 1, $\mid$ NYSE - CSE $\mid$ /NYSE Bid-Ask is an estimate of monthly volatility of the price on the NYSE relative to the CSE, normalized by the bid-ask spread on the NYSE. Clearinghouse is a stock-specific dummy variable that equals one if a stock is cleared on the NYSE. This column includes date fixed effects. Col. 2 is the same as col. 1, but |NYSE - CSE $\mid$ / NYSE Close is the volatility of the price on the NYSE minus the CSE normalized by the average closing price on both exchanges as a percentage. Col. 3 includes the effects of spillovers by including \% of Dow clearing, which is the percentage of NYSE stocks in a Dow Jones index currently centrally clearing in addition to the clearinghouse dummy. Col. 4 restricts the sample to only stocks not centrally clearing to show spillover effects and contagion risk. This regression includes variable high trading volume, which equals one if the dollar trading volume is higher than the median for all stocks over the period. This variable is then interacted with \% of Dow clearing. Col. 5 is the same as col. 4 but looks at $\mid$ NYSE - CSE $\mid$ /NYSE Close. All specifications are run with security-level fixed effects, and errors are clustered at the security level.

$$
\begin{aligned}
& * p<10 \text { percent. } \\
& * * p<5 \text { percent. } \\
& * * * p<1 \text { percent. }
\end{aligned}
$$


falls from -0.93 (col. 2 of table 3 ) to -0.37 (col. 1 of table 4 ) when normalizing by bid-ask spread, but moves only from -0.20 (col. 3 of table 3 ) to -0.16 (col. 2 of table 4 ) when normalizing by stock price. This suggests that the netting of other stocks increases the prices of stocks that have not yet cleared and that effect is picked up by the date fixed effects. The clearinghouse dummy remains marginally significant only when we normalize by the bid-ask spread. If the stocks of large firms have a high price, a low bid-ask spread, and large trading volume, this is what we would expect because traders in those securities would be more exposed to traders in the rest of the broker network. To test this explicitly, in column 3 we remove the date fixed effects and replace them with a dummy variable equal to one if the stock is centrally cleared and the percentage of all stocks centrally clearing. We find that the clearinghouse dummy is now a statistically significant -0.56 bid-ask spreads and the coefficient on the percentage of all stocks centrally clearing is a marginally significant $0.51 .^{40}$ Hence, spillover effects are likely to be important for the reduction of counterparty risk.

Since contagion risk depends on how connected traders of a given stock are to the rest of the trader network, we expect stocks trading higher volumes (relative to their average) on a particular day to be more affected by others stocks centrally clearing because they are more connected to the network. In columns 4 and 5 of table 4 we consider the effect of the percentage of stocks centrally clearing on the relative prices of stocks that have not yet cleared and include a dummy for high trading volume. ${ }^{41}$ Prior to clearing, on high-volume days, counterparty risk premium volatility is higher on the NYSE, but that effect disappears as more and more Dow stocks clear. In particular, the reduction in the counterparty risk (relative stocks on low-volume days) is 0.77 bid-ask spreads times the percentage of Dow stocks centrally clearing (col. 4) or $30 \mathrm{bp}$ times the percentage of Dow stocks centrally clearing (col. 5). If we combine the results of the high-trading volume dummy and the interaction term, we can see that prior to centrally clearing, stocks with a high trading volume on a given day are associated with large volatility in the price difference; but after centrally clearing the difference is no longer statistically significant. On lowvolume days, the volatility of the counterparty risk premium does not change in a significant way after the onset of clearing.

We run a number of robustness checks to test whether our results are driven by changes in counterparty risk coming from the introduction of clearing or changes in asynchronous trading, market liquidity, or financial

\footnotetext{
${ }^{40}$ The coefficient on the percentage of Dow clearing has a natural interpretation since it is the expected reduction in counterparty risk if 100 percent of all other stocks clear.

${ }^{41}$ The high volume dummy equals one for stocks with a trading volume higher than the median trading volume.
} 
crises. If asynchronous trading declines after the introduction of clearing, this might confound interpretation of our results. Despite the sudden decline in counterparty risk depicted by figures 5 and 6 , there is not a sudden increase in trading volume that would be consistent with a story about a decline or change in asynchronous trading for the two rival exchanges. ${ }^{42}$ The lack of any sudden change in volume is also inconsistent with results being driven by changes in relative market liquidity. In columns 1 and 2 of table 5 we do not find a significant change in relative trading volumes after the introduction of clearing. We also show in column 3 that there is little evidence of increased relative price impact since the Amihud illiquidity measure sees no statistically significant change. We also show in columns 4-6 of table 5 that all baseline results are robust to restricting our analysis to only days with at least 500 shares (five standard contracts) traded on both exchanges and including nonlinear relative measures of market liquidity on both exchanges for each stock as a control. In columns 1-3 of table A3, we show that the basic tenor of the results remains unchanged when we use daily data for all stocks on the NYSE or CSE. The results hold if we consider only stocks with at least 20 observations before and after the introduction of clearing, including estimated bid-ask spreads on the CSE as a control, and using open instead of closing prices. Again, the findings are not consistent with changes in asynchronous trading or market liquidity as drivers of the change in the relative NYSE-CSE price volatility after the introduction of clearing. We examine NYSE-CSE relative bid-ask spreads for the same securities in figure A2 and column 6 of table A3. We again do not find evidence of a sudden change in the relative market liquidity between the NYSE and CSE. ${ }^{43}$ Even though there is not a statistically significant change in any of our market liquidity proxies, it is still theoretically possible for them to affect pricing, so in column 6 of table 5 we include controls for

\footnotetext{
${ }^{42}$ For more details see fig. A1. In addition to practical frictions that could slow any transition of volume from one exchange to another, it has been shown that in the presence of limited competition, as existed during this period, market makers can earn positive profits and relationship dealers could prevent trading on either exchange from disappearing (Bernhardt et al. 2005; Desgranges and Foucault 2005).

${ }^{43}$ Work by O'Hara, Yao, and Ye (2014) suggests that in certain market environments the type of information transmitted between odd-lot trades could differ from regular transactions. Intraday trading data that would let us discern odd-lot trading are not available, but the percentage of stocks whose volume of shares does not end in a multiple of 100 shares should at least indicate the percentage of trading days with at least one odd-lot trade. Prior to the introduction of centralized clearing on the NYSE, for the NYSE and CSE, respectively, among the main sample in the paper, 90.1 percent and 91.8 percent of security trading day volumes were not multiples of 100 . While over the whole sample there ended up being significantly more security trading days with non-100-share multiples of trading on the NYSE than on the CSE, these are really concentrated in the period after 1900 when volumes rose dramatically. If we focus on just the period prior to 1900 , but after the introduction of centralized clearing on the NYSE for these securities, these were just 85.2 percent and 85.8 percent, respectively. Again these are consistent with little evidence of our effect being driven by a significant change in the types of trading occurring on each exchange.
} 


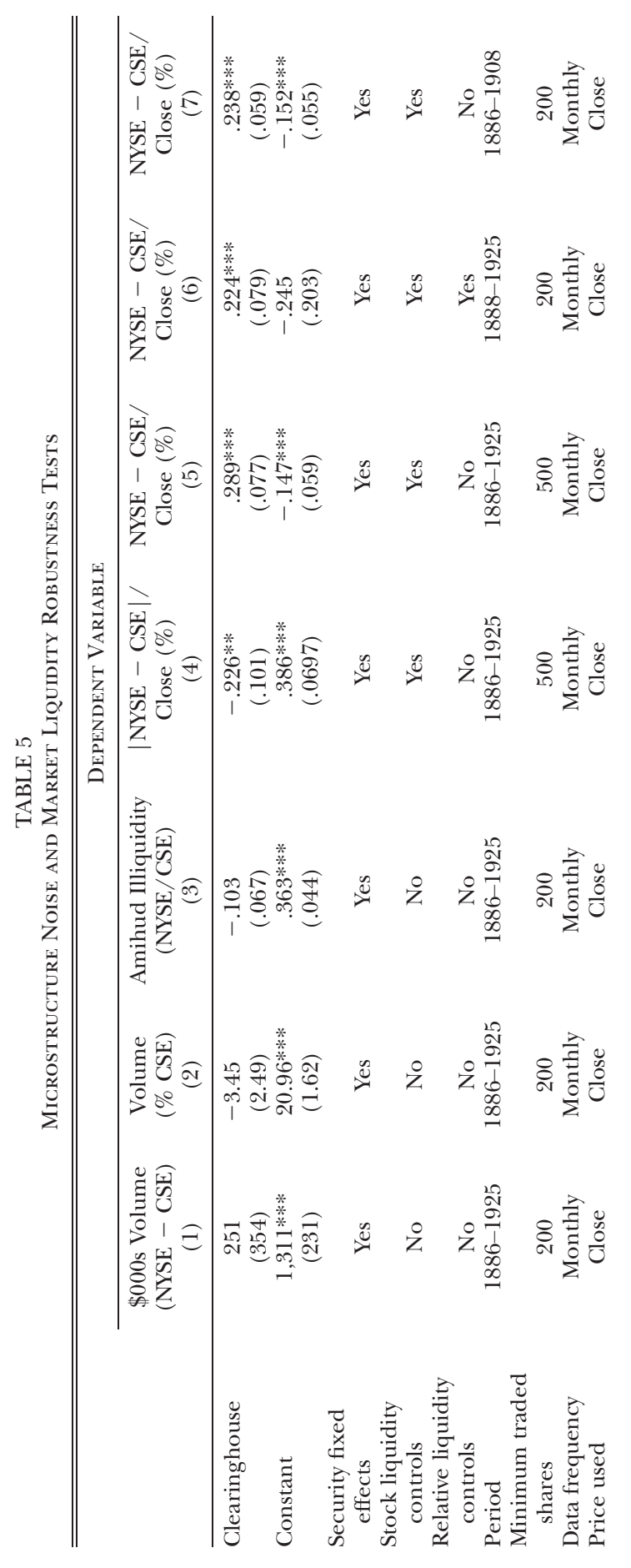




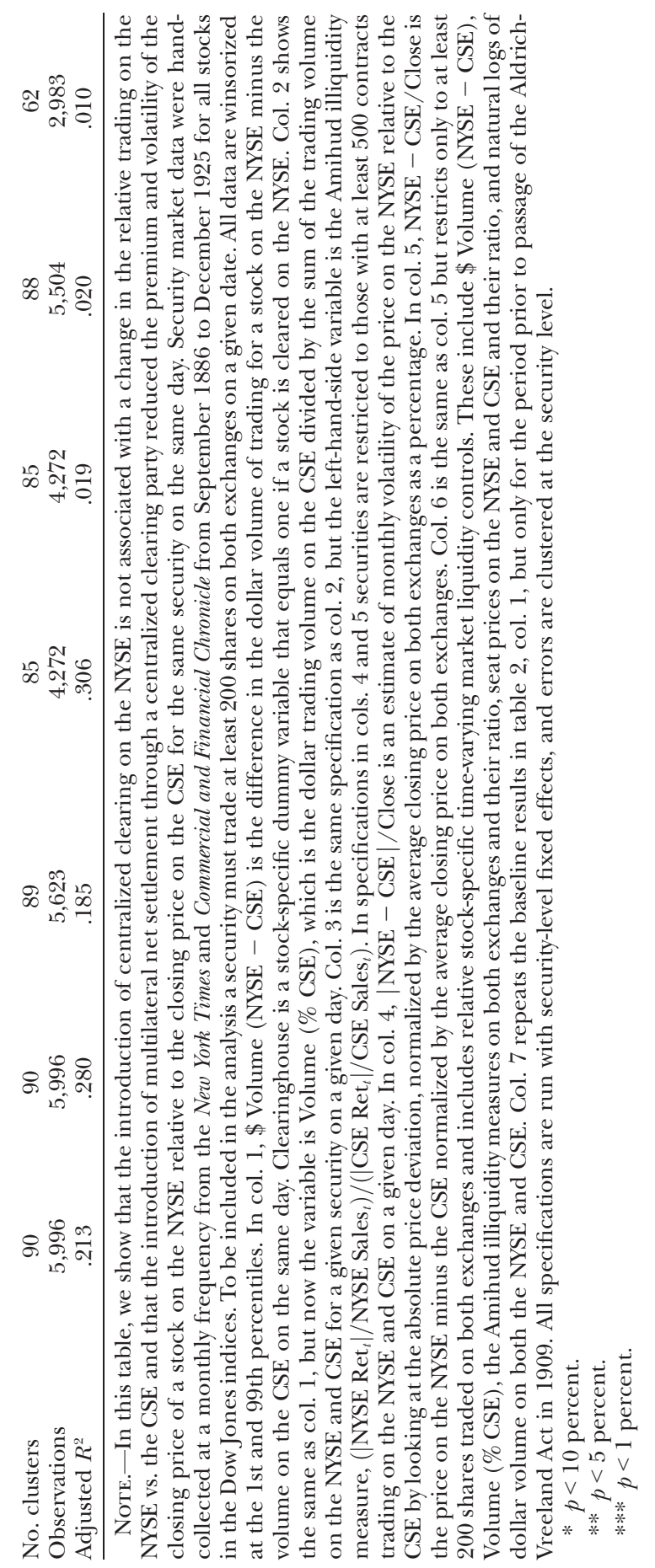


\$ Volume (NYSE-CSE), Volume (\% CSE), the Amihud illiquidity measures on both exchanges and their ratio, seat prices on the NYSE and CSE and their ratio, and natural logs of dollar volume on both the NYSE and CSE. ${ }^{44}$ The post-1983 dummy remains statistically significant, with the market liquidity controls suggesting that changes in the relative prices are not driven by any changes in the market liquidity on either exchange..$^{45}$ As a further robustness check we also rerun our analysis using identical securities simultaneously listed on the BSE as a control in column 8 of table A3 and find that results are consistent with our specifications using the CSE. We again find a decline in price dispersion after the clearinghouse is introduced on the NYSE relative to identical securities' closing prices on the BSE. The BSE introduced a clearinghouse in January of 1892. Several securities were dual-listed on the BSE and the NYSE, although not as many as the CSE. The fact that we find similar results using the BSE as a control should alleviate concerns that a CSE-specific change could be driving results.

As a robustness check for our volatility estimator, in column 7 of table A3, we use the volatility estimator based on the high and low values on each exchange as the dependent variable. According to Parkinson (1980), the difference between the high and low values is proportional to volatility. The results in column 7 suggest that stocks on the CSE that also traded on the NYSE had 4 percent lower volatility when including market liquidity controls before the introduction of the clearinghouse. The difference in volatility between NYSE and CSE dual-listed securities disappeared after the onset of centralized clearing on the Big Board. The 4 percent reduction in the volatility of NYSE securities is statistically significant and consistent with the $3.0-4.8$ percent estimate obtained using the primary volatility estimator in this paper.

Another possibility is that the reduction in counterparty risk is driven by reduced macroeconomic risk, independent of the introduction of clearing. First, we find, that relative prices were no longer sensitive to call loan rate shocks after the introduction of centralized clearing, which suggests that changes in the volatility of call loan shocks, even if they did occur, do not drive our results. The possibility also seems unlikely because in the period after centralized clearing there were numerous major panics, including the Panic of 1907, in which call loan rates increased precipitously. Indeed, the incidence of financial crises did not fall until the introduction of the Federal Reserve (see Bernstein et al. [2010] and

\footnotetext{
${ }^{44}$ Since the number of seats on the NYSE was fixed, the primary driver of seat prices was changes in trading volume. Thus changes in seat prices provide a good estimate of changes in expectations about future exchange trading volumes.

${ }^{45}$ We also found no substantive changes in corporate governance on either exchange around this time period, besides those related to the introduction of a clearinghouse on the NYSE.
} 
fig. A3). Shea $(1911,199)$ noted that "the clearing system of the exchange was severely tested during the Panic of 1907, and its efficiency was fully demonstrated." The results are also robust to restricting our analysis to the period prior to the passage of the Aldrich-Vreeland Act in 1908 and the subsequent introduction of the Federal Reserve (col. 7 of table 5). This leaves a 17-year period after the introduction of centralized clearing on the NYSE in which conditions were as ripe for financial crises as the period prior to 1892 .

Examining the period prior to 1907 also shows that the results are not driven by the introduction of the mutualization of risk on the NYSE clearinghouse in April of 1920, accusations of fraud on the CSE beginning in February of 1922, or the subsequent decline in volume on the CSE. In table 6 we explicitly examine the introduction of mutualization of risk in April 1920 prior to the accusations of fraud on the CSE in February 1922. We do not find statistically significant evidence of changes in counterparty risk driven by mutualization of risk. These results should be interpreted with caution given the limited post-mutualization period, but we do not find any evidence that the reduction in counterparty risk caused by introduction of centralized clearing in 1892 was negated, or significantly improved, by the separate introduction of mutualization of risk.

\section{Conclusion}

The dramatic rise in counterparty risk in the OTC derivatives markets during the recent financial crisis has brought the role clearinghouses play in reducing market turbulence to the forefront of public policy debate. In this paper, we show that a clearinghouse can improve financial stability in asset markets by reducing counterparty risk. We use a novel historical experiment to cleanly identify the change in counterparty risk of NYSE stocks after the introduction of a clearinghouse in 1892. We can identify the effect of introducing centralized clearing for NYSE stocks because the same securities were trading concurrently on the CSE, a rival exchange that already had centralized clearing. This is important because the introduction of centralized clearing is usually driven by macroeconomic turbulence, so that before versus after comparisons can be contaminated by changes in fundamental security value and risk. In our setting, however, changes in counterparty and illiquidity risk can be more easily attributed to the introduction of a clearinghouse. Our results suggest that prior to the introduction of net settlement on the NYSE, identical stocks on the NYSE traded at a discount of 9 bp relative to the CSE, the NYSE's principal competitor. After the establishment of a clearinghouse, NSYE stocks traded at a premium of $15 \mathrm{bp}$. The difference of $24 \mathrm{bp}$ is statistically significant. Furthermore, the change can be attributed almost entirely to the reduction in counterparty risk. 
TABLE 6

Counterparty Risk and the Introduction of NYSE Novation

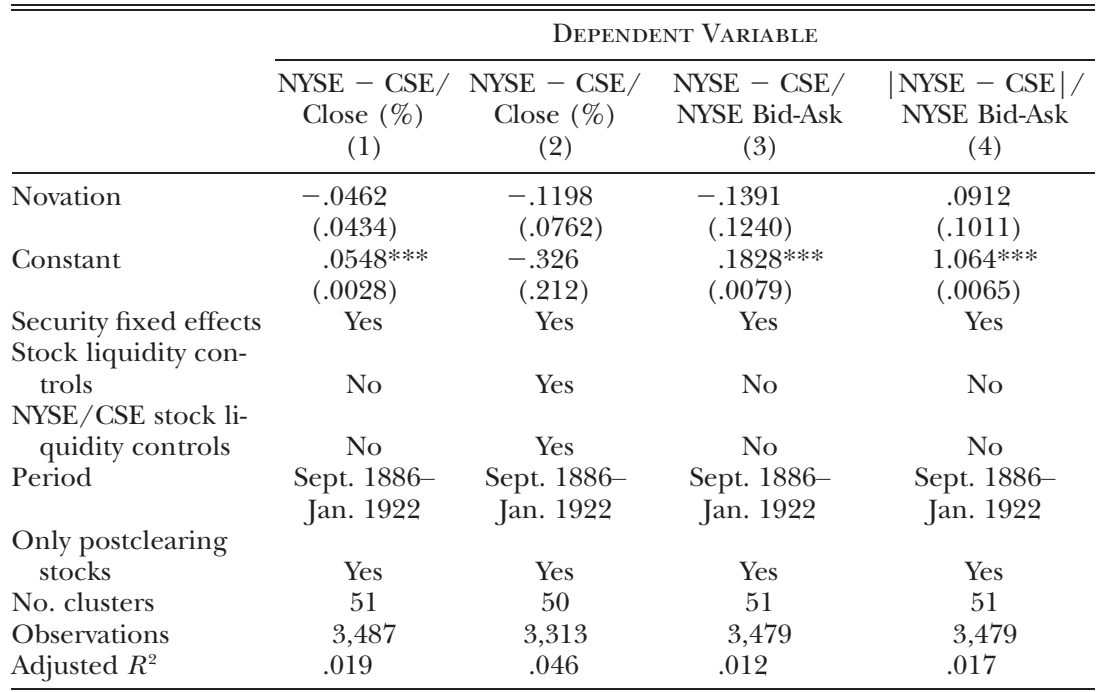

Note.- In this table we show that the introduction of novation (mutualization of risk though a centralized counterparty) on the NYSE in April 1920 does not appear to significantly affect the counterparty risk premium between the NYSE and CSE. Security market data were hand-collected and are analyzed at a monthly frequency from the New York Times and Commercial and Financial Chronicle from September 1886 to January 1922 for all stocks in the Dow Jones indices. The period February 1922-December 1925 is excluded from this analysis because of accusations of fraud on the CSE, which eventually led to its downfall, beginning with the failure of MacMasters \& Co. in February 1922. To be included in the analysis a security must trade at least 200 shares on both exchanges on a given date. All data are winsorized at the 1st and 99th percentiles. In col. 1, NYSE - CSE/Close is the price on the NYSE minus the CSE normalized by the average closing price on both exchanges, and novation is a dummy variable equal to one if the date is after April 1920. Col. 2 is the same as col. 1 but includes relative stock-specific time-varying market liquidity controls. These include \$ Volume (NYSE - CSE), Volume (\% CSE), the Amihud illiquidity measures on both exchanges and their ratio, seat prices on the NYSE and CSE and their ratio, and natural logs of dollar volume on both the NYSE and CSE. In col. 3, NYSE - CSE/NYSE BidAsk is the left-hand-side variable and is the price on the NYSE minus the CSE normalized by the bid-ask spread on the NYSE. In col. 4, |NYSE - CSE |/Close is an estimate of monthly volatility of the price on the NYSE relative to the CSE by looking at the absolute price deviation, normalized by the average closing price on both exchanges as a percentage. All specifications are run with security-level fixed effects, and errors are clustered at the security level.

$$
\begin{aligned}
& * p<10 \text { percent. } \\
& * * p<5 \text { percent. } \\
& * * * p<1 \text { percent. }
\end{aligned}
$$

Before the establishment of the NYSE clearinghouse, the NYSE traded at a premium relative to the same stocks on the CSE the majority of the time. However, when overnight collateralized borrowing rates rose sharply, prices on the NYSE fell precipitously relative to those on the CSE. A one standard deviation increase in interest rates (3.7 percentage points) re- 
duced the value of stocks on the NYSE by $8 \mathrm{bp}$, relative to identical stocks on the CSE. After the introduction of clearing, the differences between prices on the NYSE and the CSE were no longer affected by changes in these overnight funding rates. Call loan rates remained volatile, but NYSE stock return volatility fell dramatically after centralized clearing reduced settlement risk. We also use the staggered introduction of centralized clearing on the NYSE to show that at least half of this reduction in counterparty risk is driven by a reduction in contagion risk through spillovers in the trader network.

Overall, our results indicate that clearinghouses can play a significant role in improving market stability and increase asset values by reducing network contagion and counterparty risk. Two of the primary functions of clearinghouses are netting without novation and mutualization of risk. We demonstrate that even in the absence of a centralized counterparty, policies aimed at introducing centralized clearing through a clearinghouse can substantially increase netting and subsequently improve global financial stability.

\section{References}

Acharya, V., and A. Bisin. 2014. "Counterparty Risk Externality: Centralized versus Over-the-Counter Markets.” L. Econ. Theory 149:153-82.

Acharya, V., and L. Pedersen. 2005. “Asset Pricing with Liquidity Risk.” L. Financial Econ. 77:375-410.

American Bankers Association. 1910. Clearing-House Systems of the World: A Review of the Methods Used in Clearing Checks in the Principal Countries. New York: Banking Law Journal.

Amihud, Y. 2002. "Illiquidity and Stock Returns: Cross-Section and Time-Series Effects." L. Financial Markets 5 (1): 31-56.

Amihud, Y., and H. Mendelson. 1986. "Asset Pricing and the Bid-Ask Spread." L. Financial Econ. 17:223-49.

. 1991. "Liquidity, Maturity, and the Yields on U.S. Treasury Securities." I. Finance 46:1411-25.

Arora, N., P. Gandhi, and F. Longstaff. 2012. "Counterparty Credit Risk and the Credit Default Swap Market.” L. Financial Econ. 103 (2): 280-93.

Benmelech, Efraim, and Nittai K. Bergman. 2011. "Bankruptcy and the Collateral Channel." L. Finance 66 (2): 337-78.

Bernanke, B. 2011. "Clearinghouses, Financial Stability, and Financial Reform." Speech, Financial Markets Conference, Stone Mountain, GA, April 4.

Bernhardt, D., V. Dvoracek, E. Hughson, and I. Werber. 2005. "Why Do Larger Orders Receive Better Prices on the London Stock Exchange?” Rev. Financial Studies 18:1343-68.

Bernstein, A., E. Hughson, and M. Weidenmier. 2010. "Identifying the Effect of a Lender of Last Resort: Lessons from the Founding of the Fed." L. Financial Econ. 98:40-53.

Biais, B., F. Hedier, and M. Hoerova. 2012. "Clearing, Counterparty Risk and Aggregate Risk.” IMF Econ. Rev. 60:193-222. 
Brown, W., H. Mulherin, and M. Weidenmier. 2008. "Competing with the New York Stock Exchange.” O.J.E. 123 (November): 1679-1719.

Brunnermeier, M., and L. Pedersen. 2009. "Market Liquidity and Funding Liquidity." Rev. Financial Studies 22:2201-38.

Cecchetti, S., J. Gyntelberg, and M. Hollanders. 2009. "Central Counterparties for Over-the-Counter Derivatives." Bank Internat. Settlements Q. Rev. (September): $45-59$.

Corwin, S., and P. Schultz. 2012. "A Simple Way to Estimate Bid-Ask Spreads from Daily High and Low Prices.” L. Finance 67 (2): 719-60.

Coval, Joshua, and Erik Stafford. 2007. "Asset Fire Sales (and Purchases) in Equity Markets.” L. Financial Econ. 86 (2): 479-512.

Desgranges, G., and T. Foucault. 2005. "Reputation-Based Pricing and Price Improvements in Dealership Markets." L. Econ. and Bus. 57:493-527.

Duffie, Darrell. 2010. "Asset Price Dynamics with Slow-Moving Capital.” L. Finance 65:1238-68.

Duffie, D., and H. Zhu. 2011. "Does a Central Clearing Counterparty Reduce Counterparty Risk?” Rev. Asset Pricing Studies 1 (1): 74-95.

Eames, F. [1894] 1968. The New York Stock Exchange. Reprint. New York: Greenwood.

Farrell, Maurice L. 1972. The Dow Jones Averages, 1885-1970. New York: Dow Jones Books.

Garleanu, N., and L. Pedersen. 2011. "Margin-Based Asset Pricing and Deviations from the Law of One Price." Rev. Financial Studies 24 (6): 1980-2022.

Giglio, S. 2013. "Credit Default Swap Spreads and Systemic Financial Risk." Working paper, Yale School Management.

Gorton, G. 1985. "Clearinghouses and the Origin of Central Banking in the United States." I. Econ. Hist. 45 (2): 277-83.

Jones, Charles M. 2002. "A Century of Stock Market Liquidity and Trading Costs." Working paper, Columbia Bus. School.

Kroszner, R. 1999. "Can Financial Markets Privately Regulate Risk in Payments and Clearing Systems?" L. Monev, Credit and Banking 31 (August): 596-618.

Levich, R. M. 2011. "Evidence on Financial Globalization and Crises: Interest Rate Parity." In Encyclopedia of Financial Globalization, edited by Gerard Caprio. Amsterdam: Elsevier.

Lewellen, Jonathan. 2014. "The Cross Section of Expected Stock Returns." Critical Finance Rev. 4:1-44.

Loon, Y., and Z. Zhong. 2014. "The Impact of Central Clearing on Counterparty Risk, Liquidity, and Trading: Evidence from the Credit Default Swap Market." L. Financial Econ. 112 (1): 91-115.

McSherry, B., and B. Wilson. 2013. "Overcertification and the NYCHA's Clamor for a NYSE Clearinghouse.” Q. J. Austrian Econ. 16 (1): 13-26.

McSherry, B., B. Wilson, and J. McAndrews. 2017. "Net Settlement and Counterparty Risk: Evidence from the Formation of the New York Stock Exchange Clearinghouse in 1892." I. Monev. Credit and Banking 49 (6): 1273-98.

Meeker, James Edward. 1922. The Work of the Stock Exchange. New York: Ronald Press.

Menkveld, A., E. Pagnotta, and M. Zoican. 2013. "Central Clearing and Asset Prices." Discussion Working Paper no. 13-181/IV/DSF67, Tinbergen Inst.

Michie, R. 1986. "The London and New York Stock Exchanges, 1850-1914." L. Econ. Hist. 46 (March): 171-87.

Miron, J. 1986. "Financial Panics, the Seasonality of the Nominal Interest Rate, and the Founding of the Fed." A.E.R. 76:125-40. 
Moen, J., and E. Tallman. 2003. "The Call Loan Market in the US Financial System Prior to the Federal Reserve System." Working Paper no. 2003-43, Fed. Reserve Bank Atlanta.

Moser, J. 1998. "Contracting Innovations and the Evolution of Clearing and Settlement Methods at Futures Exchanges.” Working paper, Fed. Reserve Bank Chicago.

Mulherin, J., J. Netter, and J. Overdahl. 1991. "Prices Are Property: The Organization of Financial Exchanges from a Transactions Cost Perspective.” L. Law and Econ. 34:591-644.

Nelson, S. [1907] 1975. "The Consolidated Stock Exchange of New York: Its History, Organization, Machinery, and Methods." In Wall Street and the Security Markets, edited by Vincent Carooso and Robert Sobel. New York: Arno.

O'Hara, M., C. Yao, and M. Ye. 2014. "What's Not There: Odd Lots and Market Data." L. Finance 69 (October): 2199-2236.

Ott, Julia. 2004. "The 'Free and Open' 'People's Market': Public Relations at the New York Stock Exchange, 1913-1929.” Bus. and Econ. Hist. 2:1-43.

Parkinson, M. 1980. "The Extreme Value Method for Estimating the Variance of the Rate of Return." L. Bus. 53:61-65.

Pirrong, C. 2009. "The Economics of Clearing in Derivatives Markets: Netting, Asymmetric Information, and the Sharing of Default Risk through a Central Counterparty." Working paper, Univ. Houston.

Pratt, S. 1909. The Work of Wall Street. New York: Appleton.

Shea, C. 1911. The Financial Encyclopaedia: A Comprehensive Exposition of All Departments of Finance, Its Leaders, Institutions, Histories, Events and Subjects. Vol. 1. New York: Financial Encyclopaedia Co.

Silber, W. L. 1992. "Discounts on Restricted Stock: The Impact of Illiquidity on Stock Prices." Financial Analysts J. (July/August): 60-64.

Sobel, R. 2000. Curbstone Brokers: The Origins of the American Stock Exchange. New York: Beard Books.

Sprague, O. 1910. A History of Crises under the National Banking System. Washington, DC: Government Printing Office.

State of New York. 1909. "Report of Committee on Speculation in Securities and Commodities." State of New York, Albany.

Summe, K. 2012. "An Examination of Lehman Brothers' Derivatives Portfolio Postbankruptcy: Would Dodd-Frank Have Made a Difference?” In Bankruptcy Not Bailout: A Special Chapter 14, edited by K. Scott and J. Taylor. Stanford, CA: Hoover Inst. Press. 